\title{
ARIA 2016: Care pathways implementing emerging technologies for predictive medicine in rhinitis and asthma across the life cycle
}

J. Bousquet ${ }^{1,2,3,312^{*}}$, P. W. Hellings ${ }^{4}$, I. Agache ${ }^{5}$, A. Bedbrook ${ }^{2}$, C. Bachert ${ }^{6}$, K. C. Bergmann ${ }^{7,8}$, M. Bewick ${ }^{9}$, C. Bindslev-Jensen ${ }^{10}$, S. Bosnic-Anticevitch ${ }^{11}$, C. Bucca ${ }^{12}$, D. P. Caimmi ${ }^{13}$, P. A. M. Camargos ${ }^{14}$, G. W. Canonica ${ }^{15}$, T. Casale ${ }^{16}$, N. H. Chavannes ${ }^{17}$, A. A. Cruz ${ }^{18,19}$, G. De Carlo ${ }^{20}$, R. Dahl ${ }^{18}$, P. Demoly ${ }^{13,21,22}$, P. Devillier ${ }^{23}$, J. Fonseca ${ }^{24,25,26}$, W. J. Fokkens ${ }^{27}$, N. A. Guldemond ${ }^{28}$, T. Haahtela ${ }^{29}$, M. Illario ${ }^{30}$, J. Just ${ }^{31}$, T. Keil ${ }^{32,33}$, L. Klimek ${ }^{34}$, P. Kuna ${ }^{35}$, D. Larenas-Linnemann ${ }^{36}$, M. Morais-Almeida ${ }^{37}$, J. Mullol ${ }^{38}$, R. Murray ${ }^{39}$, R. Naclerio ${ }^{40}$, R. E. O'Hehir ${ }^{41,42}$, N. G. Papadopoulos ${ }^{43,44}$, R. Pawankar ${ }^{45}$, P. Potter ${ }^{46}$, D. Ryan ${ }^{47,48}$, B. Samolinski ${ }^{49}$, H. J. Schunemann ${ }^{50}$, A. Sheikh ${ }^{51}$, F. E. R. Simons ${ }^{52}$, C. Stellato ${ }^{53}$, A. Todo-Bom ${ }^{54}$, P. V. Tomazic ${ }^{55}$, A. Valiulis ${ }^{56,57,58}$, E. Valovirta59,60, M. T. Ventura ${ }^{61}$, M. Wickman ${ }^{62,63}$, I. Young ${ }^{64}$, A. Yorgancioglu ${ }^{65}$, T. Zuberbier ${ }^{7,8}$, W. Aberer ${ }^{66}$, C. A. Akdis ${ }^{67}$, M. Akdis ${ }^{67}$, I. Annesi-Maesano 21,22, J. Ankri ${ }^{3}$, I. J. Ansoteguii ${ }^{68}$, J. M. Anto69,70,71,72, S. Arnavielhe ${ }^{73}$, A. Asarnoj ${ }^{74,75}$, H. Arshad ${ }^{76}$, F. Avolio ${ }^{77}$, I. Baiardini ${ }^{15}$, C. Barbara ${ }^{78}$, M. Barbagallo ${ }^{79}$, E. D. Bateman ${ }^{80}$, B. Beghé ${ }^{81}$, E. H. Bel ${ }^{82}$, K. S. Bennoor ${ }^{83}$, M. Benson ${ }^{84}$, A. Z. Białoszewski ${ }^{49}$, T. Bieber ${ }^{85}$, L. Bjermer ${ }^{86}$, H. Blain ${ }^{87,88}$, F. Blasi ${ }^{89}$, A. L. Boner ${ }^{90}$, M. Bonini ${ }^{91}$, S. Bonini ${ }^{92}$, I. Bosse ${ }^{93}$, J. Bouchard ${ }^{94}$, L. P. Boulet ${ }^{95}$, R. Bourret ${ }^{1}$, P. J. Bousquet ${ }^{21}$, F. Braido ${ }^{15}$, A. H. Briggs ${ }^{96}$, C. E. Brightling97,98 , J. Brozek ${ }^{50}$, R. Buhl ${ }^{99}$, C. Bunu ${ }^{100}$, E. Burte ${ }^{3}$, A. Bush ${ }^{101}$, F. Caballero-Fonseca ${ }^{102}$, M. A. Calderon ${ }^{101,103}$, T. Camuzat ${ }^{104}$, V. Cardona ${ }^{105}$, P. Carreiro-Martins ${ }^{106,107}$, A. M. Carriazo ${ }^{108}$, K. H. Carlsen ${ }^{109,110}$, W. Carr ${ }^{111}$, A. M. Cepeda Sarabia ${ }^{112,113}$, M. Cesari ${ }^{114}$, L. Chatzi ${ }^{115}$, R. Chiron ${ }^{13}$, T. Chivato ${ }^{116}$, E. Chkhartishvili ${ }^{117}$, A. G. Chuchalin ${ }^{18,119}$, K. F. Chung ${ }^{103}$, G. Ciprandi ${ }^{120}$, J. Correia de Sousa ${ }^{121}$, L. Cox ${ }^{122}$, G. Crooks ${ }^{123}$, A. Custovic ${ }^{124}$, S. E. Dahlen ${ }^{125}$, U. Darsow ${ }^{126,127}$, T. Dedeu ${ }^{128,129}$, D. Deleanu ${ }^{130}$, J. A. Denburg ${ }^{131}$, G. De Vries ${ }^{132}$, A. Didier ${ }^{133}$, A. T. Dinh-Xuan ${ }^{134}$, D. Dokic ${ }^{135}$, H. Douagui ${ }^{136}$, G. Dray ${ }^{137}$, R. Dubakiene ${ }^{138}$, S. R. Durham ${ }^{139}$, G. Du Toit ${ }^{140}$, M. S. Dykewicz ${ }^{141}$, P. Eklund ${ }^{142,143}$, Y. El-Gamal ${ }^{144}$, E. Ellers ${ }^{10}$, R. Emuzyte ${ }^{56,57,58}$, J. Farrell ${ }^{145}$, A. Fink Wagner ${ }^{146}$, A. Fiocchi ${ }^{147}$, M. Fletcher ${ }^{148}$, F. Forastiere ${ }^{149}$, M. Gaga ${ }^{150}$, A. Gamkrelidze ${ }^{151}$, B. Gemicioğlu152, J. E. Gereda ${ }^{153}$, R. Gerth van Wick ${ }^{154}$, S. González Diaz ${ }^{155}$, I. Grisle ${ }^{156}$, L. Grouse ${ }^{157 \wedge}$, Z. Gutter ${ }^{158}$, M. A. Guzmán ${ }^{159}$, B. Hellquist-Dahl' ${ }^{160}$, J. Heinrich ${ }^{161}$, F. Horak ${ }^{162}$, J. O'. B. Hourihane ${ }^{163}$, M. Humbert ${ }^{164,165,166}$, M. Hyland ${ }^{167}$, G. Iaccarino ${ }^{168}$, E. J. Jares ${ }^{169}$, C. Jeandel ${ }^{2,87}$, S. L. Johnston ${ }^{170,171}$, G. Joos ${ }^{172}$, O. Jonquet ${ }^{173}$, K. S. Jung ${ }^{174}$, M. Jutel ${ }^{175}$, I. Kaidashev ${ }^{176}$, M. Khaitov ${ }^{177}$, O. Kalayci ${ }^{178}$, A. F. Kalyoncu ${ }^{179}$, P. Kardas ${ }^{180}$, P. K. Keith ${ }^{181}$, M. Kerkhof ${ }^{182}$, H. A. M. Kerstjens ${ }^{182}$, N. Khaltaev ${ }^{183}$, M. Kogevinas ${ }^{69,70,71,72}$, V. Kolek ${ }^{184}$, G. H. Koppelman ${ }^{185}$, M. L. Kowalski ${ }^{186}$, M. Kuitunen ${ }^{187}$, I. Kull ${ }^{62,63}$, V. Kvedariene ${ }^{188}$, B. Lambrecht ${ }^{189}$, S. Lau ${ }^{190}$, D. Laune ${ }^{73}$, L. T. T. Le ${ }^{191}$, P. Lieberman ${ }^{192}$, B. Lipworth ${ }^{193}$, J. Li ${ }^{194}$, K. C. Lodrup Carlsen ${ }^{109,195}$, R. Louis ${ }^{196}$, C. Lupinek ${ }^{197}$, W. MacNee ${ }^{198}$, Y. Magar ${ }^{199}$, A. Magnan ${ }^{200}$, B. Mahboub201 , D. Maier 202, I. Majer203, J. Malva204,205, P. Manning 206, E. De Manuel Keenoy ${ }^{207}$,

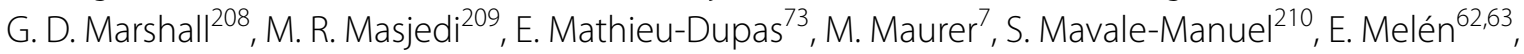
E. Melo-Gomes ${ }^{78}$, E. O. Meltzer211 , J. Mercier 212 , H. Merk²13, N. Miculinic ${ }^{214}$, F. Mihaltan²15, B. Milenkovic ${ }^{216,217}$,

\footnotetext{
*Correspondence: jean.bousquet@orange.fr

$\wedge$ Deceased

${ }^{312}$ CHRU Arnaud de Villeneuve, 371 Avenue du Doyen Gaston Giraud, 34295 Montpellier Cedex 5, France

Full list of author information is available at the end of the article
} provided you give appropriate credit to the original author(s) and the source, provide a link to the Creative Commons license, and indicate if changes were made. The Creative Commons Public Domain Dedication waiver (http://creativecommons.org/ publicdomain/zero/1.0/) applies to the data made available in this article, unless otherwise stated. 
J. Millot-Keurinck ${ }^{218}$, Y. Mohammad ${ }^{219}$, I. Momas 220,221 , R. Mösges ${ }^{222}$, A. Muraro ${ }^{223}$, L. Namazova-Baranova ${ }^{224}$, R. Nadif ${ }^{3}$, H. Neffen ${ }^{225}$, K. Nekam²6, A. Nieto ${ }^{227}$, B. Niggemann ${ }^{190}$, L. Nogueira-Silva 24,25,26,228, M. Nogues 2,218, T. D. Nyembue ${ }^{229}$, K. Ohta ${ }^{230}$, Y. Okamoto ${ }^{231}$, K. Okubo ${ }^{232}$, M. Olive-Elias ${ }^{1,28,29}$, S. Ouedraogo ${ }^{233}$, P. Paggiaro ${ }^{234}$, I. Pali-Schöll ${ }^{235}$, S. Palkonen ${ }^{20}$, P. Panzner ${ }^{236}$, A. Papi ${ }^{237}$, H. S. Park ${ }^{238}$, G. Passalacqua ${ }^{15}$, S. Pedersen ${ }^{239}$, A. M. Pereira 24,25,26,240, O. Pfaar ${ }^{34,241}$, R. Picard ${ }^{242}$, B. Pigearias ${ }^{243}$, I. Pin ${ }^{244}$, D. Plavec 245,246, W. Poh2 247, T. A. Popov²48, F. Portejoie ${ }^{2}$, D. Postma ${ }^{249}$, L. K. Poulsen ${ }^{250}$, D. Price ${ }^{251,252}$, K. F. Rabe ${ }^{253,254}$, F. Raciborskii ${ }^{49}$, G. Roberts ${ }^{255}$, C. Robalo-Cordeiro ${ }^{256}$, F. Rodenas ${ }^{257}$, L. Rodriguez-Mañas ${ }^{258}$, C. Rolland ${ }^{259}$, M. Roman Rodriguez ${ }^{260,}$ A. Romano ${ }^{261}$, J. Rosado-Pinto ${ }^{262}$, N. Rosario ${ }^{263}$, M. Rottem ${ }^{264}$, M. Sanchez-Borges ${ }^{265}$, J. Sastre-Dominguez ${ }^{266}$, G. K. Scadding ${ }^{267}$, N. Scichilone ${ }^{268}$, P. Schmid-Grendelmeier ${ }^{269}$, E. Serrano ${ }^{270}$, M. Shields ${ }^{271,272}$, V. Siroux $x^{273}$, J. C. Sisul2 ${ }^{274}$, I. Skrindo ${ }^{109,195}$, H. A. Smit ${ }^{275}$, D. Solée 276 , T. Sooronbaev ${ }^{277}$, O. Spranger ${ }^{146}$, R. Stelmach ${ }^{278}$, P. J. Sterk ${ }^{279}$, T. Strandberg ${ }^{280}$, J. Sunyer ${ }^{69,70,71,72}$, C. Thijs ${ }^{281}$, M. Triggiani ${ }^{53}$, R. Valenta ${ }^{197}$, A. Valero ${ }^{282}$, M. van Eerd ${ }^{132}$, E. van Ganse 283,284 , M. van Hague $74,75,285$, O. Vandenplas ${ }^{286}$, L. L. Varona ${ }^{287}$, B. Vellas ${ }^{114}$, G. Vezzani 288,289 , T. Vazankari ${ }^{290}$, G. Viegi ${ }^{291,292}$, T. Vontetsianos ${ }^{293}$, M. Wagenmann ${ }^{294}$, S. Walker ${ }^{295}$, D. Y. Wang ${ }^{296}$, U. Wahn ${ }^{190}$, T. Werfel ${ }^{297}$, B. Whalley ${ }^{167}$, D. M. Williams ${ }^{298}$, S. Williams ${ }^{299}$, N. Wilson ${ }^{311}$, J. Wright ${ }^{300}$, B. P. Yawn ${ }^{301}$, P. K. Yiallouros ${ }^{302}$, O. M. Yusuf ${ }^{303}$, A. Zaidi ${ }^{304}$, H. J. Zar ${ }^{305,306}$, M. E. Zernotti ${ }^{307}$, L. Zhang ${ }^{308,309}$, N. Zhong ${ }^{194}$ and M. Zidarn 310

\begin{abstract}
The Allergic Rhinitis and its Impact on Asthma (ARIA) initiative commenced during a World Health Organization workshop in 1999. The initial goals were (1) to propose a new allergic rhinitis classification, (2) to promote the concept of multi-morbidity in asthma and rhinitis and (3) to develop guidelines with all stakeholders that could be used globally for all countries and populations. ARIA—disseminated and implemented in over 70 countries globally-is now focusing on the implementation of emerging technologies for individualized and predictive medicine. MASK [MACVIA (Contre les Maladies Chroniques pour un Vieillissement Actif)-ARIA Sentinel Network] uses mobile technology to develop care pathways for the management of rhinitis and asthma by a multi-disciplinary group and by patients themselves. An app (Android and iOS) is available in 20 countries and 15 languages. It uses a visual analogue scale to assess symptom control and work productivity as well as a clinical decision support system. It is associated with an inter-operable tablet for physicians and other health care professionals. The scaling up strategy uses the recommendations of the European Innovation Partnership on Active and Healthy Ageing. The aim of the novel ARIA approach is to provide an active and healthy life to rhinitis sufferers, whatever their age, sex or socio-economic status, in order to reduce health and social inequalities incurred by the disease.
\end{abstract}

Keywords: ARIA, Rhinitis, ICT, EIP on AHA, Mobile technology, AIRWAYS ICPS

\section{Background}

The Allergic Rhinitis and its Impact on Asthma (ARIA) initiative commenced during a World Health Organization (WHO) workshop in 1999 (published in 2001) [1]. The goals were (1) to propose a new allergic rhinitis (AR) classification using persistence and severity of symptoms in order to more closely reflect patients' needs, (2) to promote the concept of multi-morbidity in asthma and rhinitis as a key factor for patient management, (3) to develop guidelines with all stakeholders, (4) to include experts from developed and developing countries and (5) to initiate global implementation among health care professionals (HCPs) and patients.
Patients, clinicians and other HCPs are confronted with various treatment choices for the management of AR. This contributes to considerable variation in clinical practice. Worldwide, patients, clinicians and other HCPs are faced with uncertainty about the relative merits and downsides of the many AR treatment options available. The first ARIA workshop report used the Shekelle evidence-based methodology $[1,2]$. It was the first guideline in chronic disease to assess multi-morbid conditions (i.e. asthma and rhinitis in the same patient). In 2008, ARIA was updated using the same evidence-based system [3]. More transparent reporting of guidelines to facilitate understanding and acceptance was needed. In its 2010 
Revision, ARIA was the first chronic respiratory disease guideline to adopt the GRADE (Grading of Recommendation, Assessment, Development and Evaluation) approach, an advanced evidence evaluation methodology [4-7]. A new revision is pending.

ARIA has been disseminated and is implemented in over 70 countries around the world [8]. It is now focusing on the implementation of emerging technologies for individualized and predictive medicine. MASK [MACVIA (Contre les Maladies Chroniques pour un Vieillissement Actif)-ARIA Sentinel NetworK] uses mobile technology to develop care pathways for the management of rhinitis and asthma by a multi-disciplinary group and by patients themselves [9].

The aim of the novel ARIA approach is to provide an active and healthy life to rhinitis sufferers, whatever their age, sex or socio-economic status in order to reduce health and social inequalities incurred by the disease.

\section{AIRWAYS ICPs: the ARIA 2016 political agenda}

In 2012, the European Commission launched the European Innovation Partnership on Active and Healthy Ageing (EIP on AHA; DG Santé and DG CONNECT) to enhance EU competitiveness and tackle societal challenges through research and innovation [10]. The B3 Action Plan is devoted to the scaling up and replication of successful innovative integrated care models for chronic diseases amongst older patients.

Chronic respiratory diseases were selected to be the pilot for chronic diseases of the EIP on AHA Action Plan B3 (Integrated care pathways for airway diseases, AIRWAYS ICPs) [11, 12] with a life cycle approach [13]. Several effective plans exist in Europe for chronic respiratory diseases, but they are rarely deployed to other regions or countries.

AIRWAYS ICPs aims to launch a collaboration to develop practical multi-sectoral care pathways (i.e. ICPs) in European countries and regions to reduce chronic respiratory disease burden, mortality and multi-morbidity, while maintaining patients' quality-of-life (QOL) $[11,14]$. AIRWAYS-ICPs proposes a feasible, achievable and manageable project (from science to guidelines and policies) using existing networks. It brings together key stakeholders including end users, public authorities, industry partners, involved in the innovation cycle, from research to adoption, as well as those engaged in standardisation and regulation. The Action Plan of AIRWAYS ICPs has been devised [11], implemented [14] and scaled up [15].

AIRWAYS ICPs is a GARD (WHO Global Alliance against Chronic Respiratory Diseases) [16] research demonstration project. Its deployment beyond Europe is carried out via GARD.
One AIRWAYS-ICPs activity is the development of multi-sectoral care pathways for rhinitis and asthma and their multi-morbidities, implementing emerging technologies for predictive medicine across the patient life cycle [13].

\section{From guidelines to integrated care pathways: MACVIA-ARIA Sentinel NetworK (MASK)}

Best practice, guideline and care pathways

A good or best practice is a technique, method, process, activity, incentive, or reward believed to be more effective than any other technique, method, process, etc. when applied to a particular condition or circumstance. A best practice can be adopted as a standard process or be used as a guideline (U.S. Dept. of Veterans Affairs [17]).

A guideline is a statement to determine a course of action. It aims to streamline particular processes according to a set routine or sound practice. By definition, following a guideline is never mandatory. Guidelines are not binding and are not enforced (U.S. Dept. of Veterans Affairs [17]).

"Clinical practice guidelines are systematically developed statements to assist practitioner and patient decisions about appropriate health care for specific clinical circumstances" (Institute of Medicine, 1990). These clinical practice guidelines define the role of specific diagnostic and treatment modalities. The statements include recommendations based on evidence intended to help HCPs and providers in their practice [18].

The Integrated Care Pathway (ICP) concept was initiated in 1985 by Zander and Bower [19]. ICPs are structured multi-disciplinary care plans detailing key steps of patient care for a given clinical problem [20]. They promote the translation of guidelines into local protocols and their subsequent application to clinical practice. An ICP forms all or part of the clinical record, documents the care given, and facilitates the evaluation of outcomes for continuous quality improvement [21]. They can help empower patients and their carers (health and social). ICPs differ from clinical practice guidelines as they are utilized by a multi-disciplinary team, and focus on the quality and co-ordination of care. ICPs need to have a mechanism for recording variations/deviations from planned care. Like guidelines, an ICP is a guide to treatment, and clinicians are free to exercise their own professional judgment as appropriate. However, any alteration to the practice identified within this ICP must be noted as a variance [22]. Variance analysis is a critical part of developing and using ICPs [23]. The resulting analysis can be used to amend the ICP itself if, for the majority of patients, the practice is different to the pathway (Table 1). 


\section{Multisectoral care pathways for rhinitis and asthma using ICT}

A large number of AR patients do not consult physicians because they think their AR symptoms are 'normal' and/or trivial. However, AR negatively impacts social life, school and work productivity [3]. Many AR patients use over the counter (OTC) drugs [24] and only a fraction have had a medical consultation. The vast majority of patients who visit GPs or specialists have moderate/ severe rhinitis [25-29]. Thus, ICPs should consider a multi-disciplinary approach as proposed by AIRWAYS ICPs (Fig. 1).

The variations/deviations of the ARIA recommendations from planned care have been assessed and several unmet needs identified. Disease severity is associated with several health outcomes, including quality of life [25-29], and should be considered in ICPs. The duration of rhinitis (intermittent/severe-persistent) is an important indicator of asthma multi-morbidity (in some but not all studies) [30], duration of AR treatment and efficacy of treatment in AR [27]. Most patients receive combinations of oral antihistamines and intra-nasal corticosteroids (INS) [31-33] which are not evaluated in guidelines using an appropriate methodology.

\section{Simple approach to assess control in allergic rhinitis}

In asthma, the management strategy is based on disease control, current treatment and future risk (exacerbations, lung function decline) [34-36]. In AR, the switch from symptom severity to disease control to guide treatment decisions has been led by ARIA and is now expanding to include MACVIA (a reference site of the EIP on AHA, EU [37]) to form an Action Plan (MACVIA-ARIA). New developments which have facilitated this process include (1) the introduction of the visual analogue scale (VAS) as the common validated language of AR control, (2) categorization of AR control using VAS score cut-offs, (3) incorporation of this VAS into simple interactive apps for both patients (ARIA Allergy Diary) and HCPs (ARIA Allergy Diary Companion) $[9,38]$ and (4) the integration of all this knowledge into ICPs deployed by the EIP on AHA [9].

The VAS represents a simple way of measuring control. It has been used in many diseases, including AR. VAS scores appear to be similar in different countries, for patients with moderate-severe intermittent or persistent rhinitis $[39,40]$. An advantage of the VAS is that it can be used in all age groups, including preschool children (guardian evaluation) [41] and the elderly [42, 43]. Furthermore, it can be used in a wide variety of languages $[39,40,42,44-48]$. VAS scores vary with ARIA AR classification in many languages $[28,44,49,50]$. A VAS score of $50 / 100 \mathrm{~mm}$ suggests moderate-severe AR [32, 51,
52], although in some studies this cut-off was $>60 \mathrm{~mm}$ [45]. The VAS has been used to define severe chronic upper airway disease (SCUAD [53]). The minimal clinically important difference (MCID) during treatment was found to be $2.3 / 10 \mathrm{~cm}$ in the French population [54] and may be generalized to other countries, but future studies may refine this cut-off score. VAS score changes appear to encompass both symptoms and disease-specific QOL $[54,55]$.

As is the case for asthma, the best control of AR should be achieved as early as possible in order to (1) improve patient satisfaction and concordance with treatment and (2) reduce the AR burden including symptoms, reduced QoL, and school and work presenteeism/absenteeism. Untreated AR can impair driving ability and put patients at risk [56]. The ultimate goal of AR control is to reduce the direct and indirect costs incurred by AR [57-60].

The variability in approaches to achieve disease control is challenging, and necessitates careful monitoring as well as the step up/step down of individualized therapeutic regimens over time. However, the challenges of managing $\mathrm{AR}$ are increased by the fact that patients do not often recognise their AR symptoms or confuse them with those of asthma or other multimorbidities such as rhinosinusitis [61]. Therefore, it is important for patients, caregivers or HCPs to be able to use an AR symptom scoring system that is simple to use and rapidly responsive to change.

The aim is to encourage effective cross communication and achieve rapid and sustained disease control. MACVIA-ARIA has produced a simple VAS-based algorithm called the ARIA Clinical Decision Support System (CDSS) using a VAS score to guide treatment decisions in a step-up/step-down approach. This CDSS provides an individualized approach to AR pharmacotherapy (depending on medication availability and resources) [62]. This approach holds the potential for optimal AR control while minimizing side effects and costs.

\section{MASK (MACVIA-ARIA Sentinel NetworK): rhinitis and asthma}

MASK-rhinitis and asthma is a simple ICT tool used to implement ICPs for AR and asthma by means of a common language (for patients and HCPs) and a CDSS. Disease control is assessed by VAS, incorporated into apps for patients (ARIA Allergy Diary) and HCPs (ARIA Allergy Diary Companion), with the utility to assess patient QoL (weekly EQ-5D) [63, 64] and school/work productivity (weekly WPAI-AS and daily VAS) $[25,65$, 66].

MASK-rhinitis and asthma will (1) allow patients and caregivers to screen for AR and asthma, and track their AR control (2) guide pharmacists in the prescription of OTC medications and referral of patients to physicians 


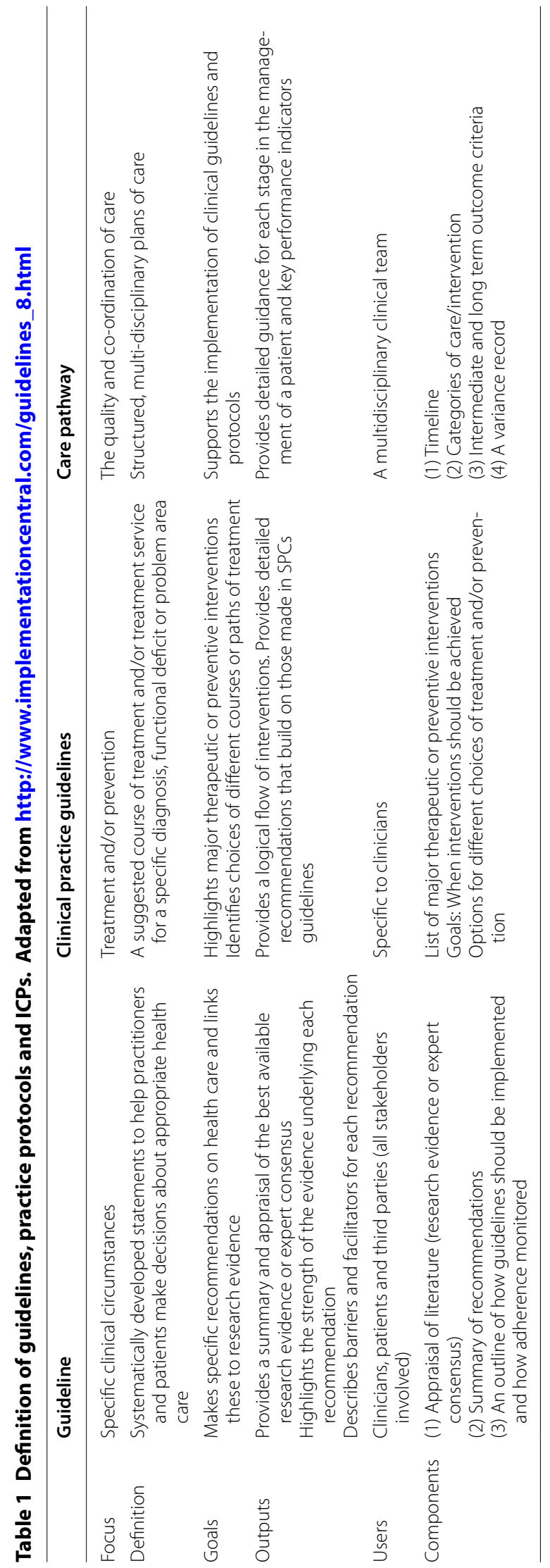




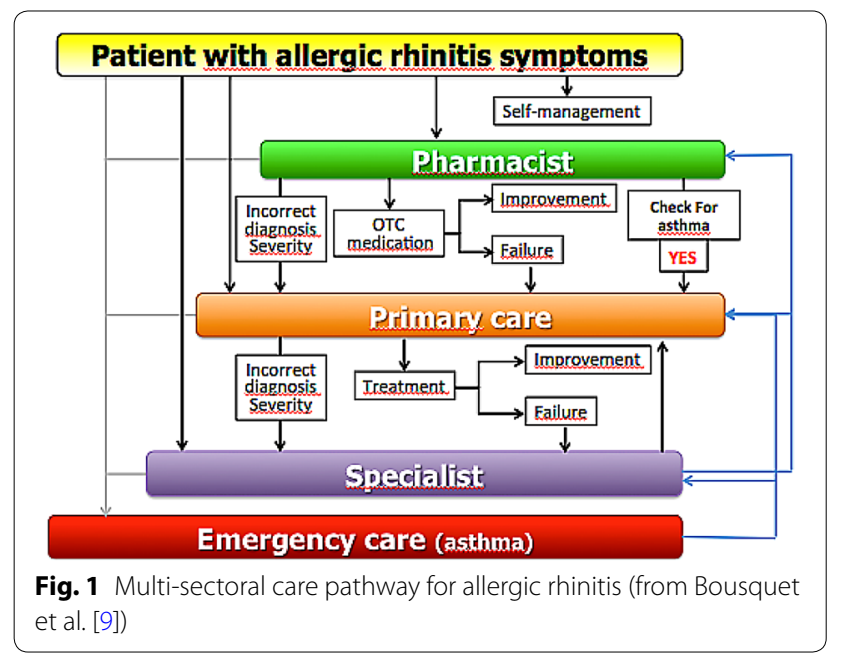

when appropriate, (3) allow primary care physicians to prescribe appropriate AR treatment, assess patients' AR control and direct follow-ups in accordance with the CDSS and (4) encourage referral to specialists and outpatient clinics, if there is failure to gain AR control at the primary care level.

MASK-rhinitis and asthma will be important for establishing care pathways across the life cycle. It will stratify patients with severe uncontrolled disease and achieve better results in prevention and intervention trials guided by the use of an individualised and predictive medicine approach.

\section{The MASK tools: the ARIA Allergy Diary and ARIA Allergy Diary Companion apps}

The ARIA Allergy Diary is freely available in $15 \mathrm{EU}$ countries, Australia, Mexico and Switzerland and in 15 languages (translated and back-translated, culturally adapted and legally compliant). It will also be deployed in Brazil, Canada and the USA. The companion app will be available in Autumn 2016.

A pilot study was completed in AR during the pollen season to assess the relevance of the ARIA Allergy Diary app. It showed the importance of the tool to stratify patients, assess their work productivity and improve quality of life (EQ-5D) (Bousquet et al., submitted). Studies in asthma are planned for the autumn and winter.

\section{Questionnaires}

ARIA Allergy Diary users fill in simple questionnaires on asthma, rhinitis and the impact of the disease (globally, on work and school, on daily activities and on sleep) upon registration (Table 2). The pilot study in around 5000 users ( $9 \%$ over 60 years of age) indicates that these questions are easily answered and can help to stratify patients with rhinitis.
Moreover, two specific questionnaires are applied every week to assess disease impact on patients' QoL (EQ-5D) $[63,64]$ and productivity at work (WPAI-AS) $[25,65,66]$.

\section{Treatments received}

A list of all treatments available for asthma, conjunctivitis and rhinitis is included in the ARIA Allergy Diary, and users select the treatment(s) they are taking. Multiple treatments may be selected, and users can update the information when (or if) their treatment changes (Fig. 2). The list has been customized for all 20 countries in which the ARIA Allergy Diary is available, using data from IMS Health. Information on allergen specific immunotherapy is also requested on the day of first use. A questionnaire on biologics for asthma is under development.

\section{Daily visual analogue scales}

Geolocalized users assess their daily symptom control using the touchscreen functionality on their smart phone to click on 5 consecutive VASs (global symptoms due to allergic diseases, rhinitis, conjunctivitis, asthma and work productivity) (Fig. 3). These scales have been validated for AR and asthma criteria [67-71] and for work productivity (Bousquet et al., in preparation).

\section{MASK-asthma}

Besides the asthma VAS, a test to measure pulmonary function is being developed. It is expected to be added to the ARIA Allergy Diary by the end of 2016.

\section{Clinical decision support system}

The MASK CDSS is incorporated into an app for HCPs (i.e. ARIA Allergy Diary Companion). This is essentially an algorithm to aid clinicians to select pharmacotherapy for patients with AR and to stratify their disease severity [62]. It uses a simple step-up/step-down individualized approach to AR pharmacotherapy and may hold the potential for optimal control of symptoms, while minimizing side effects and costs. However, its use varies depending on the availability of medications in the different countries and on resources. A CDSS for asthma is also being developed.

\section{Ethics}

The terms of use have been translated into all languages and customized according to the country's legislation. They allow the use of anonymous data for research and commercial purposes. The app has a CE registration as a medical device class 1 .

\section{Patient empowerment}

The validation of the ARIA Allergy Diary has already been accomplished (manuscript in preparation). With 
Table 2 Baseline questionnaire

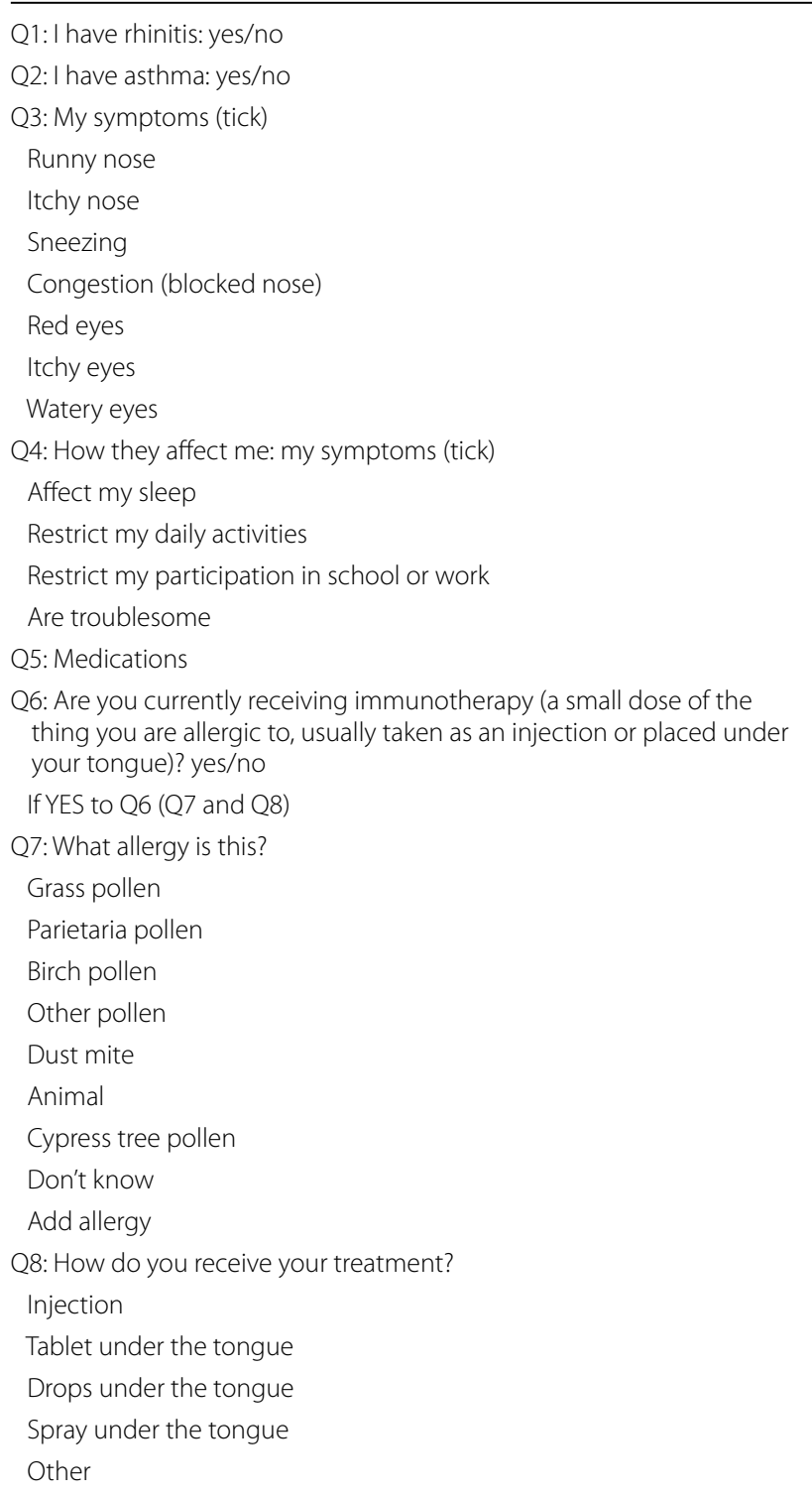

the help of patient organisations (EFA: European Federation of Allergy and Airways Diseases Patients' Associations), it will be evaluated and improved by the patients themselves.

\section{New concepts in allergic multimorbidity embedded in ARIA}

The term allergic multimorbidity is more appropriate than comorbidity since the primary allergic disease is poorly known [72].

\section{Stratification of severe allergic and/or asthma patients}

Despite the major advances in understanding allergic diseases or asthma, treatments are not effective in all patients. From a clinical perspective, implementing knowledge-based decisions on what therapeutics to use for which patients and, if relevant, in which combinations, is extremely challenging. The aspiration to provide more effective therapeutic interventions tailored to the individual remains unfulfilled because of the variable response of individuals to such interventions. Patient stratification aims at grouping patients into disease sub-groups, where the specific pathological processes involved are better defined (clinical/molecular phenotypes).

Long-term birth cohort studies are essential for understanding the life course, early predictors, risk and protective factors of allergic diseases (including asthma and rhinitis) and the complex interplay between genes and environment (including life style and socio-economic determinants) [73]. MeDALL (Mechanisms of the Development of ALLergy; EU FP7-CP-IP; Project No.: 261357; 2010-2015) attempted to better understand the complex links of allergic diseases at the clinical and mechanistic levels [74-76].

MeDALL identified a rare but severe allergy phenotype: polysensitized-multimorbid phenotype. Although multimorbidity is not always associated with allergy, studies in MeDALL [77] on children, in the PARIS cohort at 2 years of age [78], in EGEA on adults [79, 80] (Siroux, in preparation) and patient cohorts in subjects with peanut allergy [81] all show that subjects who are polysensitized and multimorbid have a very high frequency of allergic symptoms, persistent symptoms over time, more severe asthma symptoms than other phenotypes and higher total and specific IgE levels.

Taken altogether, these results indicate that asthmatic patients cannot be managed appropriately without assessing rhinitis multimorbidity and also reinforce the importance of nasal problems (rhinitis and/or rhinosinusitis) in many uncontrolled asthmatic patients [82-84].

\section{Allergic multimorbidity in old age adults}

Asthma and rhinitis often start in early age and persist in most, but not all, subjects. The expected epidemic wave of asthma and rhinitis in older adults is an insufficiently recognized problem. In Europe, over 20\% of adults suffer from AR and over 5\% from asthma. These patients are now reaching the age of 65 years and a new health problem in older adults will be to understand, detect and manage these patients. Asthma and rhinitis in older adults have specific symptoms and treatment needs, which are different from those in younger adults. These patients also suffer from multi-morbididy with high rates of poly-pharmacy reported. Integrated Care Pathways (ICPs) for rhinitis and asthma should cover the entire life cycle. 


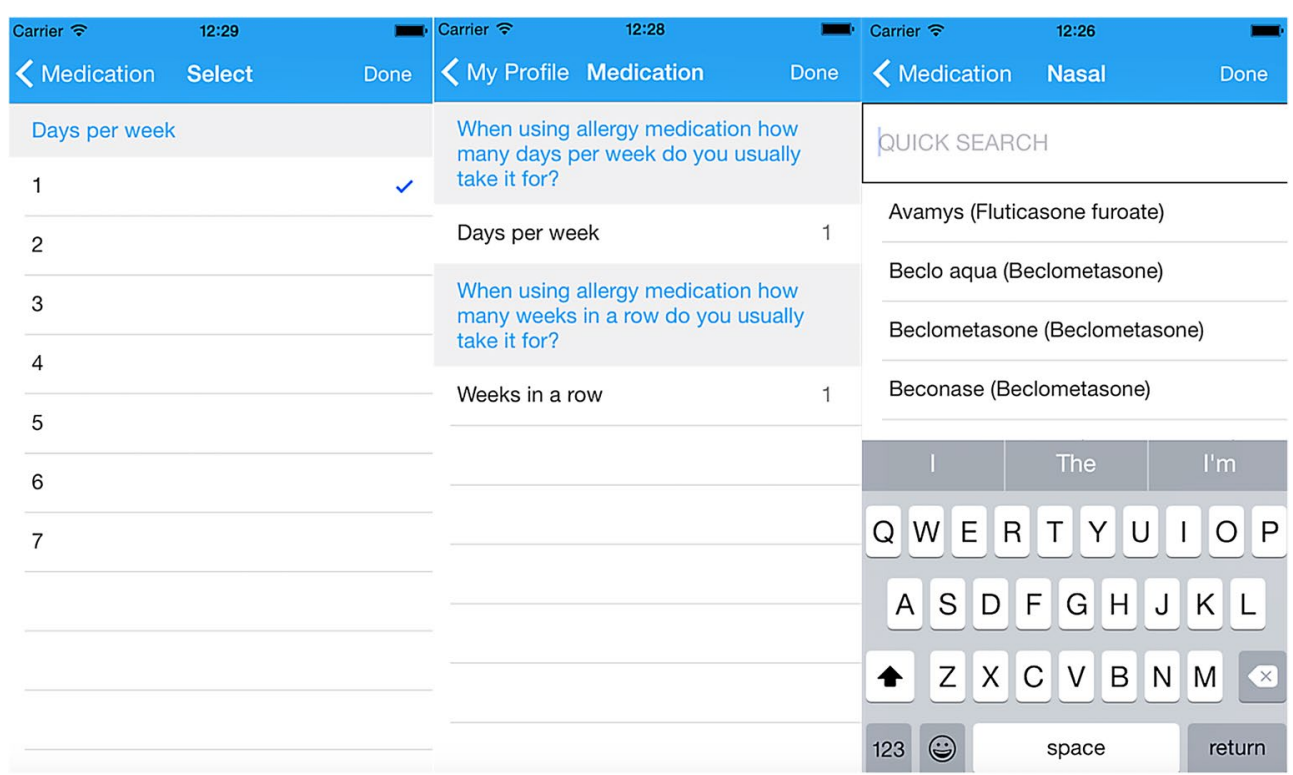

Fig. 2 Screens on medications

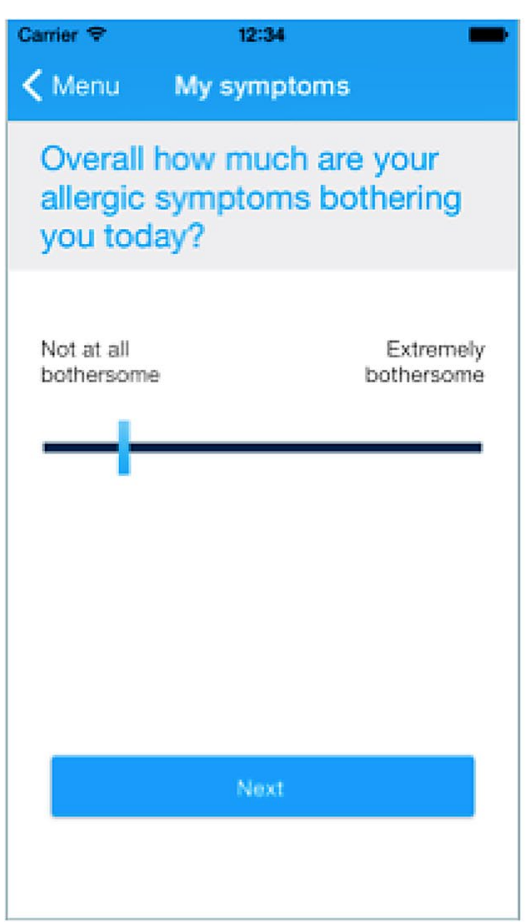

How much are your nose

symptoms bothering you today?

How much are your eye

symptoms bothering you

today?

How much are your asthma

symptoms bothering you

today?

Fig. 3 Screens on daily visual analogue scales

\section{The scaling up strategy}

The EIP on AHA has proposed a 5-step framework for developing an individual scaling up strategy: (1) what to scale up: (1-a) databases of good practices, (1-b) assessment of viability of the scaling up of good practices, (1-c) classification of good practices for local replication and (2) how to scale up: (2-a) facilitating partnerships for scaling up, (2-b) implementation of key success factors and lessons learnt, including emerging technologies for individualised and predictive medicine. This strategy has 
already been applied to the chronic respiratory diseases action plan of the EIP on AHA [15].

There is an urgent need for scaling up strategies in order to (1) avoid fragmentation, (2) improve health care delivery across Europe, (3) speed up the implementation of good practices using existing cost-effective success stories and (4) meet the EIP on AHA objectives [10].

\section{Reference Site Collaborate Network (RSCN) of the EIP on AHA}

The RSCN brings together all EIP on AHA Reference Sites, and Candidate Reference Sites, across Europe into a single forum. The aim is to promote cooperation and develop and promote areas of innovative good practice and solutions, which contribute to improved health and care outcomes for citizens across Europe. The hope is to develop sustainable economic growth and create jobs. Members of 13 EIP on AHA Reference Sites (2013) have agreed on the AIRWAYS ICPs concept and are coauthors of the paper published in Clinical Translational Allergy [15]. A meeting of all EIP on AHA Reference Sites was co-organised by the Région LR, North England [85] and the EIP on AHA Reference Site Collaborative Network to scale up AIRWAYS ICPs in all Reference Sites (October 21, 2014). 74 EIP on AHA Reference Sites have now been approved by the EU (2016). A Twinning project has also been approved by the EIP on AHA to deploy MASK in 13 Reference Sites in order to compare allergic rhinitis diagnoses by allergists in adults and older people to study phenotypes, treatments and care pathways of rhinitis.

\section{Conclusion}

ARIA has evolved from a rigorously developed guideline to a mobile technology-based implementation strategy in order to provide an active and healthy life to rhinitis sufferers, whatever their age, sex or socio-economic status with the aim to reduce health and social inequalities incurred by this very common disease globally.

\footnotetext{
Abbreviations

AIRWAYS ICPS: integrated care pathways for airway diseases; AR: allergic rhinitis; ARIA: Allergic Rhinitis and its Impact on Asthma; CDSS: Clinical Decision Support System; COPD: chronic obstructive pulmonary disease; DG: Directorate General; EAACI: European Academy of Allergy and Clinical Immunology; EIP on AHA: European Innovation Partnership on Active and Healthy Ageing; EU: European Union; FP: Framework Programme (EU); GA²LEN: Global Allergy and Asthma European Network (FP6); GARD: WHO Global Alliance against Chronic Respiratory Diseases; GRADE: Grading of Recommendation, Assessment, Development and Evaluation; HCP: health care professional; ICP: integrated care pathway; IPCRG: International Primary Care Respiratory Group; MACVIA-LR: Contre les Maladies Chroniques pour un Vieillissement Actif (fighting chronic diseases for active and healthy ageing); MASK: MACVIA-ARIA Sentinel NetworK; MeDALL: Mechanisms of the Development of ALLergy (EU FP7); $\mathrm{MOH}$ : Ministry of Health; NCD: non-communicable disease; NHS: National Health Service; RCT: randomized controlled trial; RQLQ: Rhinoconjunctivitis
}

Quality of Life Questionnaire; RSCN: Reference Site Collaborative Network; SCUAD: severe chronic upper airway disease; VAS: visual analogue scale; WHO: World Health Organization.

\section{Authors' contributions}

All authors are participating to the ARIA and AIRWAYS ICPs projects globally. All authors participated in «ARIA 2016: Care pathways implementing emerging technologies for predictive medicine in rhinitis and asthma across the life cycle». All authors read and approved the final manuscript.

\section{Author details}

${ }^{1}$ Montpellier University Hospital, Montpellier, France. ${ }^{2}$ MACVIA-France, Contre les MAladies Chroniques pour un Vleillissement Actif en France, European Innovation Partnership on Active and Healthy Ageing Reference Site, Montpellier, France. ${ }^{3}$ INSERM, U1168, Ageing and Chronic Diseases Epidemiological and Public Health Approaches, 94800 Villejuif, France. ${ }^{4}$ Laboratory of Clinical Immunology, Department of Microbiology and Immunology, KU Leuven, Louvain, Belgium. ${ }^{5}$ Transylvania University Brasov, Brasov, Romania. ${ }^{6}$ Upper Airways Research Laboratory, ENT Department, Ghent University Hospital, Ghent, Belgium. ${ }^{7}$ Allergy-Centre-Charité, Department of Dermatology and Allergy, Charité - Universitätsmedizin Berlin, Berlin, Germany. ${ }^{8}$ Global Allergy and Asthma European Network (GA2 LEN), Berlin, Germany. ${ }^{9}$ iQ4U Consultants Ltd, London, UK. ${ }^{10}$ Department of Dermatology and Allergy Centre, Odense University Hospital, Odense, Denmark. ${ }^{11}$ Woolcock Institute of Medical Research, University of Sydney and Sydney Local Health District, Glebe, NSW, Australia. ${ }^{12}$ University Pneumology Unit-AOU Molinette, Hospital City of Health and Science of Torino, Turin, Italy.

${ }^{13}$ Department of Respiratory Diseases, Montpellier University Hospital, Montpellier, France. ${ }^{14}$ Department of Pediatrics, Medical School, Federal University of Minas Gerais, Belo Horizonte, Brazil. ${ }^{15}$ Asthma and Allergy Clinic, Humanitas University, Rozzano, Milan, Italy. ${ }^{16}$ Division of Allergy/Immunology, University of South Florida, Tampa, FL, USA. ${ }^{17}$ Department of Public Health and Primary Care, Leiden University Medical Center, Leiden, The Netherlands. ${ }^{18}$ ProAR - Nucleo de Excelencia em Asma, Federal University of Bahia, Salvador, Brazil. ${ }^{19}$ GARD Executive Committee, Salvador, Bahia, Brazil. ${ }^{20}$ EFA European Federation of Allergy and Airways Diseases Patients' Associations, Brussels, Belgium. ${ }^{21}$ EPAR U707 INSERM, Paris, France. ${ }^{22}$ EPAR UMR-S UPMC, Paris VI, Paris, France. ${ }^{23}$ Laboratoire de Pharmacologie Respiratoire UPRES EA220, Hôpital Foch, Suresnes Université Versailles, Saint-Quentin, France.

${ }^{24}$ Center for Research in Health Technologies and Information Systems - CINTESIS, Universidade do Porto, Porto, Portugal. ${ }^{25}$ Allergy Unit, Instituto CUF Porto e Hospital CUF Porto, Porto, Portugal. ${ }^{26}$ Health Information and Decision Sciences Department - CIDES, Faculdade de Medicina, Universidade do Porto, Rua Dr. Plácido da Costa, s/n, 4200-450 Porto, Portugal. ${ }^{27}$ Department of Otorhinolaryngology, Academic Medical Centre, Amsterdam, The Netherlands. ${ }^{28}$ Institute of Health Policy and Management IBMG, Erasmus University, Rotterdam, The Netherlands. ${ }^{29}$ Skin and Allergy Hospital, Helsinki University Hospital, Helsinki, Finland. ${ }^{30}$ Federico II University Hospital Naples (R\&D and DISMET), Naples, Italy. ${ }^{31}$ Allergology Department, Centre de I'Asthme et des Allergies, Hôpital d'Enfants Armand-Trousseau (APHP), Sorbonne Universités, UPMC Univ Paris 06, UMR_S 1136, Institut Pierre Louis d'Epidémiologie et de Santé Publique, Equipe EPAR, 75013 Paris, France.

32 Institute of Social Medicine, Epidemiology and Health Economics, Charité - Universitätsmedizin Berlin, Berlin, Germany. ${ }^{33}$ Institute for Clinical Epidemiology and Biometry, University of Wuerzburg, Würzburg, Germany.

${ }^{34}$ Center for Rhinology and Allergology, Wiesbaden, Germany. ${ }^{35}$ Division of Internal Medicine, Asthma and Allergy, Barlicki University Hospital, Medical University of Lodz, Lodz, Poland. ${ }^{36}$ Clínica de Alergia, Asma y Pediatría, Hospital Médica Sur, Mexico City, Mexico. ${ }^{37}$ Allergy and Clinical Immunology Department, Hospital CUF-Descobertas, Lisbon, Portugal. ${ }^{38}$ ENT Department, Hospital Clinic, Clinical and Experimental Respiratory Immunoallergy, IDIBAPS, CIBERES, Universitat de Barcelona, Barcelona, Catalonia, Spain. ${ }^{39}$ MedScript Ltd, Dundalk, County Louth, Ireland. ${ }^{40}$ Section of Otolaryngology-Head and Neck Surgery, The University of Chicago Medical Center and The Pritzker School of Medicine, The University of Chicago, Chicago, IL, USA. ${ }^{41}$ Department of Allergy, Immunology and Respiratory Medicine, Alfred Hospital and Central Clinical School, Monash University, Melbourne, VIC, Australia. ${ }^{42}$ Department of Immunology, Monash University, Melbourne, VIC, Australia. ${ }^{43}$ Center for Pediatrics and Child Health, Institute of Human Development, Royal Manchester Children's Hospital, University of Manchester, Manchester, UK. 
${ }^{44}$ Allergy Department, 2nd Pediatric Clinic, Athens General Children's Hospital "P\&A Kyriakou", University of Athens, Athens, Greece. ${ }^{45}$ Department of Pediatrics, Nippon Medical School, Tokyo, Japan. ${ }^{46}$ Allergy Diagnostic and Clinical Research Unit, University of Cape Town Lung Institute, Cape Town, South Africa. ${ }^{47}$ Woodbrook Medical Centre, Loughborough, UK. ${ }^{48}$ Allergy and Respiratory Research Group, The University of Edinburgh, Edinburgh, UK. ${ }^{49}$ Department of Prevention of Environmental Hazards and Allergology, Medical University of Warsaw, Warsaw, Poland. ${ }^{50}$ Department of Clinical Epidemiology and Biostatistics, McMaster University, Hamilton, ON, Canada. ${ }^{51}$ Allergy and Respiratory Research Group, Centre for Population Health Sciences, The University of Edinburgh Medical School, Edinburgh, UK. ${ }^{52}$ Department of Pediatrics and Child Health, Department of Immunology, Faculty of Medicine, University of Manitoba, Winnipeg, MB, Canada. ${ }^{53}$ Division of Allergy and Clinical Immunology, University of Salerno, Salerno, Italy. ${ }^{54}$ Centre of Pneumology, Faculty of Medicine, University of Coimbra, Coimbra, Portugal. ${ }^{55}$ Department of ENT, Medical University of Graz, Graz, Austria. ${ }^{56}$ Clinic of Children's Diseases, Faculty of Medicine, Vilnius University, Vilnius, Lithuania. ${ }^{57}$ Public Health Institute, Vilnius University, Vilnius, Lithuania. ${ }^{58}$ European Academy of Paediatrics (EAP/UEMS-SP), Brussels, Belgium. ${ }^{59}$ Department of Lung Diseases and Clinical Allergology, University of Turku, Turku, Finland. ${ }^{60}$ Allergy Clinic, Terveystalo, Turku, Finland ${ }^{61}$ Unit of Geriatric Immunoallergology, University of Bari Medical School, Bari, Italy. ${ }^{62}$ Sachs' Children and Youth Hospital, Södersjukhuset, Stockholm, Sweden. ${ }^{63}$ Institute of Environmental Medicine, Karolinska Institutet, Stockholm, Sweden. ${ }^{64}$ Queen's University, Belfast, Northern Ireland, UK. ${ }^{65}$ Department of Pulmonology, Celal Bayar University, Manisa, Turkey. ${ }^{66}$ Department of Dermatology, Medical University of Graz, Graz, Austria. ${ }^{67}$ Swiss Institute of Allergy and Asthma Research (SIAF), University of Zurich, Davos, Switzerland. ${ }^{68}$ Department of Allergy and Immunology, Hospital Quirón Bizkaia, Erandio, Spain. ${ }^{69}$ Barcelona Institute for Global Health (ISGlobal), Barcelona, Spain. ${ }^{70}$ IMIM (Hospital del Mar Research Institute), Barcelona, Spain. ${ }^{71}$ CIBER Epidemiología y Salud Pública (CIBERESP), Barcelona, Spain. ${ }^{72}$ Universitat Pompeu Fabra (UPF), Barcelona, Spain. ${ }^{73}$ Kyomed, Montpellier, France. ${ }^{74}$ Clinical Immunology and Allergy Unit, Department of Medicine Solna, Karolinska Institutet, Stockholm, Sweden. ${ }^{75}$ Department of Pediatric Pulmonology and Allergy, Astrid Lindgren Children's Hospital, Karolinska University Hospital, Stockholm, Sweden. ${ }^{76}$ David Hide Asthma and Allergy Research Centre, Isle of Wight, UK. ${ }^{77}$ Regionie Puglia, Bari, Italy. ${ }^{78}$ Faculdade de Medicina de Lisboa, Portuguese National Programme for Respiratory Diseases (PNDR), Lisbon, Portugal. ${ }^{79}$ Geriatric Unit, Department of Internal Medicine (DIBIMIS), University of Palermo, Palermo, Italy. ${ }^{80}$ Department of Medicine, University of Cape Town, Cape Town, South Africa. ${ }^{81}$ Section of Respiratory Disease, Department of Oncology, Haematology and Respiratory Diseases, University of Modena and Reggio Emilia, Modena, Italy. ${ }^{82}$ Department of Respiratory Medicine, Academic Medical Center (AMC), University of Amsterdam, Amsterdam, The Netherlands. ${ }^{83}$ Department of Respiratory Medicine, National Institute of Diseases of the Chest and Hospital, Dhaka, Bangladesh. ${ }^{84}$ Centre for Individualized Medicine, Department of Pediatrics, Faculty of Medicine, Linköping University, 58185 Linköping, Sweden. ${ }^{85}$ Department of Dermatology and Allergy, Rheinische FriedrichWilhelms-University Bonn, Bonn, Germany. ${ }^{86}$ Department of Respiratory Medicine and Allergology, University Hospital, Lund, Sweden. ${ }^{87}$ Department of Geriatrics, Montpellier University Hospital, Montpellier, France. ${ }^{88}$ EA 2991, Euromov, University Montpellier, Montpellier, France. ${ }^{89}$ Department of Pathophysiology and Transplantation, IRCCS Fondazione Ca'Granda Ospedale Maggiore Policlinico, University of Milan, Milan, Italy. ${ }^{90}$ Pediatric Department, University of Verona Hospital, Verona, Italy. ${ }^{91}$ Department of Public Health and Infectious Diseases, Sapienza University of Rome, Rome, Italy. ${ }^{92}$ Second University of Naples and Institute of Translational Medicine, Italian National Research Council, Naples, Italy. ${ }^{93}$ La Rochelle, France. ${ }_{94}$ Montreal, QC, Canada. ${ }^{95}$ Quebec Heart and Lung Institute, Laval University, Quebec City, QC, Canada. ${ }^{96}$ Health Economics and Health Technology Assessment, Institute of Health and Wellbeing, University of Glasgow, Glasgow, UK. ${ }^{97}$ Institute of Lung Health, Respiratory Biomedical Unit, University Hospitals of Leicester NHS Trust, Leicestershire, UK. ${ }^{98}$ Department of Infection, Immunity and Inflammation, University of Leicester, Leicester, UK. ${ }^{99}$ Universitätsmedizin der Johannes Gutenberg-Universität Mainz, Mainz, Germany. 100 University of Medicine and Pharmacy Victor Babes, Timisoara, Romania. 101 Royal Brompton Hospital NHS, Imperial College London, London, UK. 102 Centro Medico Docente La Trinidad, Caracas, Venezuela. ${ }^{103}$ National Heart and Lung Institute, Imperial College London, London, UK. ${ }^{104}$ Montpellier,
Région Languedoc Roussillon, France. ${ }^{105}$ S. Allergologia, S. Medicina Interna, Hospital Vall d'Hebron, Barcelona, Spain. ${ }^{106}$ CEDOC, Respiratory Research Group, Nova Medical School, Campo dos Martires da Patria, Lisbon, Portugal. 107 Serviço de Imunoalergologia, Centro Hospitalar de Lisboa Central, EPE, Lisbon, Portugal. ${ }^{108}$ Regional Ministry of Health of Andalusia, Seville, Spain. ${ }^{109}$ Department of Paediatrics, Oslo University Hospital, Oslo, Norway. 110 University of Oslo, Oslo, Norway. ${ }^{111}$ Allergy and Asthma Associates of Southern California, Mission Viejo, CA, USA. ${ }^{112}$ Allergy and Immunology Laboratory, Metropolitan University, Simon Bolivar University, Barranquilla, Colombia. ${ }^{113}$ SLaai, Sociedad Latinoamericana de Allergia, Asma e Immunologia, Cartagena, Colombia. ${ }^{114}$ Gérontopôle de Toulouse, 31059 Toulouse, France. ${ }^{115}$ Department of Social Medicine, Faculty of Medicine, University of Crete, Heraklion, Crete, Greece. ${ }^{116}$ School of Medicine, University CEU San Pablo, Madrid, Spain. ${ }^{117}$ Chachava Clinic, David Tvildiani Medical University-AIETI Medical School, Grigol Robakidze University, Tbilisi, Georgia. ${ }^{118}$ Pulmonolory Research Institute FMBA, Moscow, Russia. ${ }^{119}$ GARD Executive Committee, Moscow, Russia. ${ }^{120}$ Medicine Department, IRCCS-Azienda Ospedaliera Universitaria San Martino, Genoa, Italy. ${ }^{121}$ ICVS/3B's-PT Government Associate Laboratory, Life and Health Sciences, Research Institute (ICVS), School of Health Sciences, University of Minho, Braga, Portugal.

${ }^{122}$ Department of Medicine, Nova Southeastern University, Davie, FL, USA.

${ }^{123}$ EIP on AHA, European Innovation Partnership on Active and Healthy Ageing, Reference Site, Scottish Centre for Telehealth and Telecare, NHS 24, Glasgow, UK. ${ }^{124}$ Department of Pediatric, Imperial College London, London, UK. ${ }^{125}$ The Centre for Allergy Research, The Institute of Environmental Medicine, Karolinska Institutet, Stockholm, Sweden. ${ }^{126}$ Department of Dermatology and Allergy, Technische Universität München, Munich, Germany. ${ }^{127}$ ZAUM-Center for Allergy and Environment, Helmholtz Center Munich, Munich, Germany. ${ }^{128}$ AQUAS, Barcelona, Spain. ${ }^{129}$ EUREGHA, European Regional and Local Health Association, Brussels, Belgium. ${ }^{130}$ Allergology and Immunology Discipline, "Luliu Hatieganu” University of Medicine and Pharmacy, Cluj-Napoca, Romania. ${ }^{131}$ Division of Clinical Immunology and Allergy, Department of Medicine, McMaster University, Hamilton, ON, Canada. ${ }^{132}$ Peercode DV, Amsterdam, The Netherlands. ${ }_{133}$ Respiratory Diseases Department, Rangueil-Larrey Hospital, Toulouse, France. ${ }^{134}$ Service de Physiologie Respiratoire, Hôpital Cochin, Université Paris-Descartes, Assistance Publique-Hôpitaux de Paris, Paris, France. 135 University Clinic of Pulmology and Allergy, Medical Faculty, Ss Cyril and Methodius University, Skopje, Republic of Macedonia. ${ }^{136}$ Service de Pneumo-Allergologie, Centre Hospitalo-Universitaire de Béni-Messous, Algers, Algeria. ${ }^{137}$ Ecole des Mines, Alès, France. ${ }^{138}$ Medical Faculty, Vilnius University, Vilnius, Lithuania. ${ }^{139}$ Allergy and Clinical Immunology Section, National Heart and Lung Institute, Imperial College London, London, UK. ${ }^{140}$ Guy's and St Thomas' NHS Trust, Kings College London, London, UK. ${ }^{141}$ Section of Allergy and Immunology, Saint Louis University School of Medicine, Saint Louis, MO, USA. ${ }^{142}$ Computing Science Department, Umeå University, Umeå, Sweden. ${ }^{143}$ Four Computing Oy, Halikko, Finland. ${ }^{144}$ Pediatric Allergy and Immunology Unit, Ain Shams University, Cairo, Egypt. ${ }^{145}$ Department of Health, Social Services and Public Safety, Belfast, Northern Ireland, UK. ${ }^{146}$ Global Allergy and Asthma Platform GAAPP, Altgasse 8-10, 1130 Vienna, Austria. ${ }^{147}$ Division of Allergy, Department of Pediatric Medicine, The Bambino Gesù Children's Research Hospital Holy See, Rome, Italy. ${ }^{148}$ Education for Health, Warwick, UK. ${ }^{149}$ Department of Epidemiology, Regional Health Service Lazio Region, Rome, Italy. ${ }^{150}$ Athens Chest Hospital, Athens, Greece. ${ }^{151}$ National Center for Disease Control and Public Health of Georgia, Tbilisi, Georgia. ${ }^{152}$ Department of Pulmonary Diseases, Cerrahpasa Faculty of Medicine, Istanbul University, Istanbul, Turkey. ${ }^{153}$ Allergy and Immunology Division, Clinica Ricardo Palma, Lima, Peru. ${ }^{154}$ Section of Allergology, Department of Internal Medicine, Erasmus MC, Rotterdam, The Netherlands. ${ }^{155}$ Universidad Autónoma de Nuevo León, San Nicolás de los Garza, Mexico. ${ }^{156}$ Center of Tuberculosis and Lung Diseases, Latvian Association of Allergists, Riga, Latvia. ${ }^{157}$ Faculty of the Department of Neurology, University of Washington School of Medicine, Seattle, WA, USA. ${ }^{158}$ National eHealth Centre, University Hospital Olomouc, Olomouc, Czech Republic. ${ }^{159}$ Immunology and Allergy Division Clinical Hospital, University of Chile, Santiago, Chile. ${ }^{160}$ Department of Respiratory Diseases, Odense University Hospital, Odense, Denmark. 161 Institute of Epidemiology l, Helmholtz Zentrum München - German Research Center for Environmental Health, Neuherberg, Germany. ${ }^{162}$ Vienna Challenge Chamber, Vienna, Austria. ${ }^{163}$ Department of Paediatrics and Child Health, University College Cork, Cork, Ireland. ${ }^{164}$ Université Paris-Sud, Le Kremlin Bicêtre, France. ${ }^{165}$ Service de Pneumologie, Hôpital Bicêtre, Le Kremlin 
Bicêtre, France. ${ }^{166}$ Inserm UMR_S999, Le Kremlin Bicêtre, France. ${ }^{167}$ School of Psychology, Plymouth University, Plymouth, UK. ${ }^{168}$ Department of Medicine and Surgery, University of Salerno, Baronissi, Italy. ${ }^{169}$ Libra Foundation, Buenos Aires, Argentina. ${ }^{170}$ Airway Disease Infection Section, National Heart and Lung Institute, Imperial College London, London, UK. ${ }^{171}$ MRC \& Asthma UK Centre in Allergic Mechanisms of Asthma, London, UK. ${ }^{172}$ Department of Respiratory Medicine, Ghent University Hospital, Ghent, Belgium. ${ }^{173}$ Medical Commission, Montpellier University Hospital, Montpellier, France. ${ }^{174}$ Hallym University Sacred Heart Hospital, Hallym University College of Medicine, Anyang, Gyeonggi-do, South Korea. ${ }^{175}$ Department of Clinical Immunology, Wrocław Medical University, Wrocław, Poland. ${ }^{176}$ Ukrainian Medical Stomatological Academy, Poltava, Ukraine. ${ }^{177}$ Laboratory of Molecular Immunology, National Research Center, Institute of Immunology, Federal Medicobiological Agency, Moscow, Russia. ${ }^{178}$ Pediatric Allergy and Asthma Unit, School of Medicine, Hacettepe University, Ankara, Turkey. ${ }^{179}$ Immunology and Allergy Division, Department of Chest Diseases, School of Medicine, Hacettepe University, Ankara, Turkey. ${ }^{180}$ First Department of Family Medicine, Medical University of Lodz, Lodz, Poland. ${ }^{181}$ Department of Medicine, McMaster University, Health Sciences Centre 3V47, 1280 Main Street West, Hamilton, ON, Canada. 182 Department of Pulmonary Diseases, University Medical Center Groningen, University of Groningen, Groningen, The Netherlands. ${ }^{183}$ GARD, Geneva, Switzerland. ${ }^{184}$ Department of Respiratory Medicine, Faculty of Medicine and Dentistry, University Hospital Olomouc, Olomouc, Czech Republic. ${ }^{185}$ Department of Pediatric Pulmonology and Pediatric Allergology, Beatrix Children's Hospital, GRIAC Research Institute, University Medical Center Groningen, University of Groningen, Groningen, The Netherlands. ${ }^{186}$ Department of Immunology, Rheumatology and Allergy and HARC, Medical University of Lodz, Lodz, Poland. ${ }^{187}$ Children's Hospital, University of Helsinki, Helsinki, Finland. ${ }^{88}$ Clinic of Infectious, Chest Diseases, Dermatology and Allergology, Vilnius University, Vilnius, Lithuania. ${ }^{199}$ VIB Inflammation Research Center, Ghent University, Ghent, Belgium. ${ }^{190}$ Department for Pediatric Pneumology and Immunology, Charité Medical University, Berlin, Germany. ${ }^{191}$ University of Medicine and Pharmacy, Hochiminh City, Vietnam. 192 Divisions of Allergy and Immunology, Department of Internal Medicine and Pediatrics, University of Tennessee College of Medicine, Germantown, TN, USA. ${ }^{193}$ Scottish Centre for Respiratory Research, Cardiovascular and Diabetes Medicine, Medical Research Institute, Ninewells Hospital, University of Dundee, Dundee, UK. ${ }^{194}$ State Key Laboratory of Respiratory Diseases, Guangzhou Institute of Respiratory Disease, The First Affiliated Hospital of Guangzhou Medical University, Guangzhou, China. ${ }^{195}$ Institute of Clinical Medicine, Faculty of Medicine, University of Oslo, Oslo, Norway. ${ }^{196}$ Department of Pulmonary Medicine, CHU Sart-Tilman, Liege, Belgium. ${ }^{197}$ Division of Immunopathology, Department of Pathophysiology and Allergy Research, Center for Pathophysiology, Infectiology and Immunology, Medical University of Vienna, Vienna, Austria. ${ }^{198}$ The Queen's Medical Research Institute, University of Edinburgh, Edinburgh, UK. ${ }^{199}$ Service de Pneumo-allergologie, Hôpital Saint-Joseph, Paris, France. ${ }^{200}$ Service de Pneumologie, UMR INSERM, UMR1087 and CNR 6291, l'institut du Thorax, University of Nantes, Nantes, France. ${ }^{201}$ Department of Pulmonary Medicine, Rashid Hospital, Dubai, UAE. ${ }^{202}$ Biomax Informatics AG, Munich, Germany. ${ }^{203}$ Department of Respiratory Medicine, University of Bratislava, Bratislava, Slovakia. ${ }^{204}$ Institute of Biomedical Imaging and Life Sciences (IBILI), Faculty of Medicine, University of Coimbra, Coimbra, Portugal. ${ }^{205}$ Ageing@Coimbra EIP-AHA Reference Site, Coimbra, Portugal. ${ }^{206}$ Department of Medicine (RCSI), Bon Secours Hospital, Glasnevin, Dublin, Ireland. ${ }^{207}$ Kronikgune, Basque Region, Spain. ${ }^{208}$ Laboratory of Behavioral Immunology Research, Division of Clinical Immunology and Allergy, The University of Mississippi Medical Center, Jackson, MS, USA. ${ }^{209}$ Tobacco Control Research Centre, Iranian Anti Tobacco Association, Tehran, Iran. ${ }^{210}$ Department of Paediatrics, Maputo Central Hospital, Maputo, Mozambique. ${ }^{211}$ Allergy and Asthma Medical Group and Research Center, San Diego, CA, USA. 212 Department of Physiology, CHRU, PhyMedExp, INSERM U1046, CNRS UMR 9214, University Montpellier, Montpellier, France. ${ }^{213}$ Hautklinik - Klinik für Dermatologie \& Allergologie, Universitätsklinikum der RWTH Aachen, Aachen, Germany. ${ }^{214}$ Croatian Pulmonary Society, Zagreb, Croatia. ${ }^{215}$ National Institute of Pneumology M. Nasta, Bucharest, Romania. ${ }^{216}$ Faculty of Medicine, University of Belgrade, Belgrade, Serbia. ${ }^{217}$ Serbian Association for Asthma and COPD, Belgrade, Serbia. ${ }^{218}$ Caisse d'assurance retraite et de la santé au travail du Languedoc-Roussillon (CARSAT-LR), Montpellier, France. ${ }^{219}$ National Center for Research in Chronic Respiratory Diseases, Tishreen University School of Medicine, Latakia, Syria. ${ }^{220}$ Department of Public Health and Health Products, EA 4064, Paris Descartes University-Sorbonne Paris Cité, Paris, France.
${ }^{221}$ Paris Municipal Department of Social Action, Childhood, and Health, Paris, France. 222 Institute of Medical Statistics, Informatics and Epidemiology, Medical Faculty, University of Cologne, Cologne, Germany. ${ }^{223}$ Food Allergy Referral Centre Veneto Region, Department of Women and Child Health, Padua General University Hospital, Padua, Italy. ${ }^{224}$ Scientific Centre of Children's Health Under the Russian Academy of Medical Sciences, Moscow, Russia. ${ }^{225}$ Hospital de Niños Orlando Alassia, Santa Fe, Argentina. ${ }^{226}$ Hospital of the Hospitaller Brothers in Buda, Budapest, Hungary. ${ }^{227}$ Neumología y Alergología Infantil, Hospital La Fe, Valencia, Spain. ${ }^{228}$ Department of Internal Medicine, Centro Hospitalar Sao Joao, Porto, Portugal. ${ }^{229}$ ENT Department, University Hospital of Kinshasa, Kinshasa, Congo. ${ }^{230}$ National Hospital Organization, Tokyo National Hospital, Tokyo, Japan. ${ }^{231}$ Department of Otorhinolaryngology, Chiba University Hospital, Chiba, Japan. ${ }^{232}$ Department of Otolaryngology, Nippon Medical School, Tokyo, Japan. ${ }^{233}$ Centre Hospitalier Universitaire Pédiatrique Charles de Gaulle, Ouagadougou, Burkina Faso. ${ }^{234}$ Cardio-Thoracic and Vascular Department, University Hospital of Pisa, Pisa, Italy. ${ }^{235}$ Department of Comparative Medicine, Messerli Research Institute of the University of Veterinary Medicine, Medical University, Vienna, Austria. ${ }^{236}$ Department of Immunology and Allergology, Faculty of Medicine and Faculty Hospital in Pilsen, Charles University in Prague, Pilsen, Czech Republic. ${ }^{237}$ Respiratory Medicine, Department of Medical Sciences, University of Ferrara, Ferrara, Italy. ${ }^{238}$ Department of Allergy and Clinical Immunology, Ajou University School of Medicine, Suwon, South Korea. ${ }^{239}$ University of Southern Denmark, Kolding, Denmark. ${ }^{240}$ Allergy Unit, CUF-Porto Hospital and Institute, Porto, Portugal. ${ }^{241}$ Department of Otorhinolaryngology, Head and Neck Surgery, Universitätsmedizin Mannheim, Medical Faculty Mannheim, Heidelberg University, Mannheim, Germany. ${ }^{242}$ Conseil Général de I'Economie, Ministère de l'Economie, de l'Industrie et du Numérique, Paris, France. ${ }^{243}$ Société de Pneumologie de Langue Française, Espace francophone de Pneumologie, Paris, France. ${ }^{244}$ Département de pédiatrie, CHU de Grenoble, Grenoble, France. ${ }^{245}$ Children's Hospital Srebrnjak, Zagreb, Croatia. ${ }^{246}$ School of Medicine, University J.J. Strossmayer, Osijek, Croatia. ${ }^{247}$ Karl Landsteiner Institute for Clinical and Experimental Pneumology, Hietzing Hospital, Vienna, Austria. ${ }^{248}$ Clinic of Allergy and Asthma, Medical University Sofia, Sofia, Bulgaria. ${ }^{249}$ University Medical Center Groningen, University of Groningen, Groningen, The Netherlands. ${ }^{250}$ Laboratory of Medical Allergology, Allergy Clinic, Copenhagen University Hospital at Gentofte, Copenhagen, Denmark. ${ }^{251}$ Academic Centre of Primary Care, University of Aberdeen, Aberdeen, Scotland, UK. ${ }^{252}$ Research in Real-Life, Cambridge, UK. ${ }^{253}$ LungenClinic Grosshansdorf, Airway Research Center North, German Center for Lung Research (DZL), Grosshansdorf, Germany. ${ }^{254}$ Department of Medicine, Christian Albrechts University, Airway Research Center North, German Center for Lung Research (DZL), Kiel, Germany. ${ }^{255}$ NHS Foundation Trust, University Hospitals of Southampton, Southampton, UK. ${ }^{256}$ Centre of Pneumology, Coimbra University Hospital, Coimbra, Portugal. 257 Polibienestar Research Institute, University of Valencia, Valencia, Spain. ${ }^{258}$ Department of Geriatrics, Getafe University Hospital, Madrid, Spain. ${ }^{259}$ Association Asthme et Allergie, Paris, France. ${ }^{260}$ Primary Care Respiratory Research Unit, Institutode Investigación Sanitaria de Palma IdisPa, Palma de Mallorca, Spain. ${ }^{261}$ Allergy Unit, Complesso Integrato Columbus, Rome, Italy. ${ }^{262}$ Serviço de Imunoalergologia, Hospital da Luz, Lisbon, Portugal. ${ }^{263}$ Hospital de Clinicas, University of Parana, Curitiba, Brazil. ${ }^{264}$ Division of Allergy Asthma and Clinical Immunology, Emek Medical Center, Afula, Israel. ${ }^{265}$ Allergy and Clinical Immunology Department, Centro Médico-Docente La Trinidad and Clínica El Avila, Caracas, Venezuela. ${ }^{266}$ Faculty of Medicine, Autononous University of Madrid, Madrid, Spain. ${ }^{267}$ The Royal National TNE Hospital, University College London, London, UK. ${ }^{268}$ DIBIMIS, University of Palermo, Palermo, Italy. ${ }^{269}$ Allergy Unit, Department of Dermatology, University Hospital of Zurich, Zurich, Switzerland. ${ }^{270}$ Otolaryngology and Head and Neck Surgery, CHU Rangueil-Larrey, Toulouse, France. ${ }^{271}$ Child Health, Queen's University, Belfast, Northern Ireland, UK. ${ }^{272}$ Royal Belfast Hospital for Sick Children, Belfast, Northern Ireland, UK. ${ }^{273}$ INSERM, Université Grenoble Alpes, IAB, U 1209, Team of Environmental Epidemiology Applied to Reproduction and Respiratory Health, Université Joseph Fourier, Grenoble, France. ${ }^{274}$ Sociedad Paraguaya de Alergia Asma e Inmunologia, Asunción, Paraguay. ${ }^{275}$ Julius Center of Health Sciences and Primary Care, University Medical Center Utrecht, University of Utrecht, Utrecht, The Netherlands. ${ }^{276}$ Division of Allergy, Clinical Immunology and Rheumatology, Department of Pediatrics, Federal University of São Paulo, São Paulo, Brazil. ${ }^{277}$ Kyrgyzstan National Centre of Cardiology and Internal Medicine, Euro-Asian Respiratory Society, Bishkek, Kyrgyzstan. 278 Pulmonary Division, Heart Institute (InCor), Hospital da Clinicas da 
Faculdade de Medicina da Universidade de Sao Paulo, São Paulo, Brazil. ${ }^{279}$ Academic Medical Centre, University of Amsterdam, Amsterdam, The Netherlands. ${ }^{280}$ European Union Geriatric Medicine Society (EUGMS), Helsinki, Finland. ${ }^{281}$ Department of Epidemiology, CAPHRI School of Public Health and Primary Care, Maastricht University, Maastricht, The Netherlands. 282 Pneumology and Allergy Department, Hospital Clínic, Clinical and Experimental Respiratory Immunoallergy, IDIBAPS, Barcelona, Spain. ${ }^{283}$ PELyon, Lyon, France. ${ }^{284}$ HESPER 7425, Health Services and Performance Resarch, Université Claude Bernard Lyon, Villeurbanne, France. ${ }^{285}$ University Hospital, Stockholm, Sweden. ${ }^{286}$ Department of Chest Medicine, Centre Hospitalier Universitaire UCL Namur, Université Catholique de Louvain, Yvoir, Belgium. 287 Philippines Society of Allergy, Asthma and Immunology, Manila, Philippines. ${ }^{288}$ Pulmonary Unit, Department of Cardiology, Thoracic and Vascular Medicine, Arcispedale S. Maria Nuova/IRCCS, Research Hospital, Reggio Emilia, Italy. ${ }^{289}$ Regional Agency for Health and Social Care, Reggio Emilia, Italy. ${ }^{290}$ Finnish Lung Association (FILHA), Helsinki, Finland. ${ }^{291}$ Pulmonary Environmental Epidemiology Unit, CNR Institute of Clinical Physiology, Pisa, Italy. ${ }^{292}$ CNR Institute of Biomedicine and Molecular Immunology "A. Monroy", Palermo, Italy. ${ }^{293}$ Sotiria Hospital, Athens, Greece. ${ }^{294}$ Department of Otorhinolaryngology, HNO-Klinik, Universitätsklinikum Düsseldorf, Düsseldorf, Germany. ${ }^{295}$ Asthma UK, Mansell Street, London, UK. ${ }^{296}$ Department of Otolaryngology, Yong Loo Lin School of Medicine, National University of Singapore, Singapore, Singapore. ${ }^{297}$ Division of Immunodermatology and Allergy Research, Department of Dermatology and Allergy, Hannover Medical School, Hannover, Germany. ${ }^{298}$ Eshelman School of Pharmacy, University of North Carolina, Chapel Hill, NC, USA. ${ }^{299}$ IPCRG, Aberdeen, Scotland, UK. ${ }^{300}$ Bradford Institute for Health Research, Bradford Royal Infirmary, Bradford, UK. ${ }^{301}$ Department of Research, OImsted Medical Center, Rochester, MN, USA. ${ }^{302}$ Medical School, University of Cyprus, Nicosia, Cyprus. ${ }^{303}$ The Allergy and Asthma Institute, Lahore, Pakistan. ${ }^{304}$ Social Sciences, University of Southampton, Southampton, UK. ${ }^{305}$ Department of Paediatrics and Child Health, Red Cross Children's Hospital, University of Cape Town, Cape Town, South Africa. ${ }^{306}$ MRC Unit on Child and Adolescent Health, University of Cape Town, Cape Town, South Africa. ${ }^{307}$ Universidad Católica de Córdoba, Córdoba, Argentina. ${ }^{308}$ Department of Otolaryngology Head and Neck Surgery, Beijing TongRen Hospital, Beijing, China. ${ }^{309}$ Beijing Institute of Otolaryngology, Beijing, China. ${ }^{310}$ University Clinic of Respiratory and Allergic Diseases, Golnik, Slovenia. ${ }^{311}$ Northern Health Alliance, Newcastle, UK. ${ }^{312}$ CHRU Arnaud de Villeneuve, 371 Avenue du Doyen Gaston Giraud, 34295 Montpellier Cedex 5, France.

\section{Acknowledgements}

Member of the dissemination of MASK in 20 countries: J. Bousquet, P. Hellings, A. Bedbrook, C. Bachert, K.C. Bergmann, M. Bewick, C. Bindslev-Jensen, S. Bosnic-Anticevitch, D. Caimmi, P.A.M. Camargos, G.W. Canonica, T. Casale, N.H. Chavannes, A.A. Cruz, G. De Carlo, R. Dahl, P. Demoly, P. Devillier, J. Fonseca, W.J. Fokkens, T. Haahtela, J. Just, L. Klimek, P. Kuna, D. Larenas-Linnemann, M. Morais-Almeida, J. Mullol, R. Murray, R. Naclerio, R.E. O'Hehir, N.G. Papadopoulos, P. Potter, D. Ryan, B. Samolinski, H.J. Schunemann, A. Sheikh, F.E.R. Simons, P.V. Tomazic, A. Valiulis, E. Valovirta, M. Wickman, A. Yorgancioglu, T. Zuberbier, S. Arnavielle, G. De Vries, G. Dray, M. van Eerd.

Twinning of MASK in Reference Sites of the European Innovation Partnership on Active and Healthy Ageing: J. Bousquet, A. Bedbrook, M. Bewick, C. Bindslev-Jensen, C. Bucca, D. Caimmi, N.H. Chavannes, P. Demoly, J. Fonseca, N.A. Guldemond, M. Illario, P. Kuna, M. Morais-Almeida, J. Mullol, R. Murray, C. Stellato, A. Todo-Bom, M.T. Ventura, I. Young, A. Yorgancioglu, S. Arnavielle, E. Ellers, J. Farrell, R. Gerth van Wick, Z. Gutter, G. laccarino, M. Olive-Elias.

\section{Competing interests}

The authors declare that they have no competing interests.

\section{Consent for publication}

Obtained from all authors.

\section{Ethics approval and consent to participate}

Review, none needed.

\section{Funding}

European Innovation Partnership on Active and Healthy Ageing Reference Site MACVIA-France, EU Structural and Development Fund Languedoc-Roussillon, ARIA.
Received: 10 November 2016 Accepted: 5 December 2016

Published online: 30 December 2016

\section{References}

1. Bousquet J, Van Cauwenberge P, Khaltaev N. Allergic rhinitis and its impact on asthma. J Allergy Clin Immunol. 2001;108(5 Suppl):S147-334.

2. Shekelle PG, Woolf SH, Eccles M, Grimshaw J. Clinical guidelines: developing guidelines. BMJ. 1999;318(7183):593-6.

3. Bousquet J, Khaltaev N, Cruz AA, Denburg J, Fokkens WJ, Togias A, et al. Allergic Rhinitis and its Impact on Asthma (ARIA) 2008 update (in collaboration with the World Health Organization, GA(2)LEN and AllerGen). Allergy. 2008;63(Suppl 86):8-160.

4. Brozek JL, Akl EA, Alonso-Coello P, Lang D, Jaeschke R, Williams JW, et al. Grading quality of evidence and strength of recommendations in clinical practice guidelines. Part 1 of 3. An overview of the GRADE approach and grading quality of evidence about interventions. Allergy. 2009;64(5):669-77.

5. Brozek JL, Baena-Cagnani CE, Bonini S, Canonica GW, Rasi G, van Wijk RG, et al. Methodology for development of the Allergic Rhinitis and its Impact on Asthma guideline 2008 update. Allergy. 2008;63(1):38-46.

6. Brozek JL, Bousquet J, Baena-Cagnani CE, Bonini S, Canonica GW, Casale $\mathrm{TB}$, et al. Allergic Rhinitis and its Impact on Asthma (ARIA) guidelines: 2010 revision. J Allergy Clin Immunol. 2010;126(3):466-76.

7. Padjas A, Kehar R, Aleem S, Mejza F, Bousquet J, Schunemann HJ, et al. Methodological rigor and reporting of clinical practice guidelines in patients with allergic rhinitis: QuGAR study. J Allergy Clin Immunol. 2014;133(3):777-783.e4.

8. Bousquet J, Schunemann HJ, Samolinski B, Demoly P, Baena-Cagnani CE, Bachert C, et al. Allergic Rhinitis and its Impact on Asthma (ARIA): achievements in 10 years and future needs. J Allergy Clin Immunol. 2012;130(5):1049-62.

9. Bousquet J, Schunemann HJ, Fonseca J, Samolinski B, Bachert C, Canonica GW, et al. MACVIA-ARIA Sentinel Network for allergic rhinitis (MASK-rhinitis): the new generation guideline implementation. Allergy. 2015;70(11):1372-92.

10. Bousquet J, Michel J, Standberg T, Crooks G, lakovidis I, Gomez M. The European Innovation Partnership on Active and Healthy Ageing: the European Geriatric Medicine introduces the EIP on AHA Column. Eur Geriatr Med. 2014;5(6):361-2.

11. Bousquet J, Addis A, Adcock I, Agache I, Agusti A, Alonso A, et al. Integrated care pathways for airway diseases (AIRWAYS-ICPS). Eur Respir J. 2014;44(2):304-23.

12. Bousquet J, Barbara C, Bateman E, Bel E, Bewick M, Chavannes N, et al. AIRWAYS ICPS (European Innovation Partnership on Active and Healthy Ageing) from concept to implementation. Eur Respir J. 2016;47(4):102833. doi: 10.1183/13993003.01856-2015.

13. Bousquet J, Anto JM, Berkouk K, Gergen P, Antunes JP, Auge P, et al. Developmental determinants in non-communicable chronic diseases and ageing. Thorax. 2015;70(6):595-7.

14. Bousquet J, Barbara C, Bateman E, Bel E, Bewick M, Chavannes NH, et al. AIRWAYS-ICPs (European Innovation Partnership on Active and Healthy Ageing) from concept to implementation. Eur Respir J. 2016;47(4):1028-33.

15. Bousquet J, Farrell J, Crooks G, Hellings P, Bel E, Bewick M, et al. Scaling up strategies of the Chronic Respiratory Disease programme of the European Innovation Partnership on Active and Healthy Ageing (Action Plan B3-Area 5). Clin Transl Allergy. 2016;6:29. doi:10.1186/ s13601-016-0116-9.

16. Bousquet J, Dahl R, Khaltaev N. Global alliance against chronic respiratory diseases. Allergy. 2007;62(3):216-23.

17. TRM Glossary. One-VA technical reference model v14.10. US Department of Veteran Affairs. http://www.vagov/trm/TRMGlossaryPageasp. 2014.

18. National Center for Complementary and Alternative Medicine (NCCAM). National Institutes of Health. Clinical practice guidelines. http://nccam. nih.gov/health/providers/clinicalpractice.htm. 2014.

19. Zander K. Historical development of outcomes-based care delivery. Crit Care Nurs Clin N Am. 1998;10(1):1-11. 
20. Campbell H, Hotchkiss R, Bradshaw N, Porteous M. Integrated care pathways. BMJ. 1998;316(7125):133-7.

21. Overill S. A practical guide to care pathways. J Integr Care. 1998;2:93-8.

22. Integrated Care Pathways users in Scotland (ICPUS). A workbook for people starting to develop integrated care pathways. http://www.icpus. org.uk2007.

23. How to produce and evaluate an integrated care pathway (ICP): information for staff. Great Ormond Street Hospital for Children. www.gosh.nhs.uk. 2010.

24. ARIA in the pharmacy: management of allergic rhinitis symptoms in the pharmacy. Allergic rhinitis and its impact on asthma. Allergy. 2004:59(4):373-87.

25. Bousquet J, Neukirch F, Bousquet PJ, Gehano P, Klossek JM, Le Gal M, et al. Severity and impairment of allergic rhinitis in patients consulting in primary care. J Allergy Clin Immunol. 2006;117(1):158-62.

26. Bousquet J, Annesi-Maesano I, Carat F, Leger D, Rugina M, Pribil C, et al. Characteristics of intermittent and persistent allergic rhinitis: DREAMS study group. Clin Exp Allergy. 2005;35(6):728-32.

27. Bousquet PJ, Devillier P, Tadmouri A, Mesbah K, Demoly P, Bousquet J. Clinical relevance of cluster analysis in phenotyping allergic rhinitis in a real-life study. Int Arch Allergy Immunol. 2015;166(3):231-40.

28. del Cuvillo A, Montoro J, Bartra J, Valero A, Ferrer M, Jauregui I, et al. Validation of ARIA duration and severity classifications in Spanish allergic rhinitis patients—-the ADRIAL cohort study. Rhinology. 2010;48(2):201-5.

29. Jauregui I, Davila I, Sastre J, Bartra J, del Cuvillo A, Ferrer M, et al. Validation of ARIA (Allergic Rhinitis and its Impact on Asthma) classification in a pediatric population: the PEDRIAL study. Pediatr Allergy Immunol. 2011;22(4):388-92.

30. Cruz AA, Popov T, Pawankar R, Annesi-Maesano I, Fokkens W, Kemp J, et al. Common characteristics of upper and lower airways in rhinitis and asthma: ARIA update, in collaboration with GA(2)LEN. Allergy. 2007;62(Suppl 84):1-41.

31. Canonica GW, Bousquet J, Mullol J, Scadding GK, Virchow JC. A survey of the burden of allergic rhinitis in Europe. Allergy. 2007;62(Suppl 85):17-25.

32. Bousquet PJ, Demoly P, Devillier P, Mesbah K, Bousquet J. Impact of allergic rhinitis symptoms on quality of life in primary care. Int Arch Allergy Immunol. 2013;160(4):393-400.

33. Price D, Scadding G, Ryan D, Bachert C, Canonica GW, Mullol J, et al. The hidden burden of adult allergic rhinitis: UK healthcare resource utilisation survey. Clin Transl Allergy. 2015;5:39.

34. Expert Panel Report 3 (EPR-3): guidelines for the diagnosis and management of asthma-summary report 2007. J Allergy Clin Immunol. 2007;120(5 Suppl):S94-138.

35. O'Byrne PM, Reddel HK, Eriksson G, Ostlund O, Peterson S, Sears MR, et al. Measuring asthma control: a comparison of three classification systems. Eur Respir J. 2010;36(2):269-76.

36. Reddel HK, Bateman ED, Becker A, Boulet LP, Cruz AA, Drazen JM, et al. A summary of the new GINA strategy: a roadmap to asthma control. Eur Respir J. 2015;46(3):622-39. doi:10.1183/13993003.00853-2015.

37. Bousquet J, Bourquin C, Augé $\mathrm{P}$, Domy P, Bringer J, Camuzat T, et al. MACVIA-LR Reference Site of the European Innovation Partnership on Active and Healthy Ageing. Eur Geriatr Med. 2014;5(6):406-15.

38. Bourret R, Bousquet J, Mercier J, Camuzat T, Bedbrook A, Demoly P, et al. MASK rhinitis, a single tool for integrated care pathways in allergic rhinitis. World Hosp Health Serv. 2015:51(3):36-9.

39. Bousquet J, Bachert C, Canonica GW, Mullol J, Van Cauwenberge P, Bindslev Jensen C, et al. Efficacy of desloratadine in intermittent allergic rhinitis: a GALEN study. Allergy. 2009;64:1516-23.

40. Bousquet J, Bachert C, Canonica GW, Mullol J, Van Cauwenberge P, Jensen $\mathrm{CB}$, et al. Efficacy of desloratadine in persistent allergic rhinitis-a GA(2) LEN study. Int Arch Allergy Immunol. 2010;153(4):395-402.

41. Morais-Almeida M, Santos N, Pereira AM, Branco-Ferreira M, Nunes C, Bousquet J, et al. Prevalence and classification of rhinitis in preschool children in Portugal: a nationwide study. Allergy. 2013;68(10):1278-88

42. Morais-Almeida M, Pite H, Pereira AM, Todo-Bom A, Nunes C, Bousquet J, et al. Prevalence and classification of rhinitis in the elderly: a nationwide survey in Portugal. Allergy. 2013;68(9):1150-7.

43. Klimek L, Bachert C, Mosges R, Munzel U, Price D, Virchow JC, et al. Effectiveness of MP29-02 for the treatment of allergic rhinitis in real-life: results from a noninterventional study. Allergy Asthma Proc. 2015;36(1):40-7.
44. Ohta K, Bousquet PJ, Aizawa H, Akiyama K, Adachi M, Ichinose M, et al. Prevalence and impact of rhinitis in asthma. SACRA, a cross-sectional nation-wide study in Japan. Allergy. 2011;66(10):1287-95.

45. Larenas-Linnemann D, Dinger $H$, Shah-Hosseini K, Michels A, Mosges R. Over diagnosis of persistent allergic rhinitis in perennial allergic rhinitis patients: a nationwide study in Mexico. Am J Rhinol Allergy. 2013;27(6):495-501.

46. Shao J, Cui YX, Zheng YF, Peng HF, Zheng ZL, Chen JY, et al. Efficacy and safety of sublingual immunotherapy in children aged 3-13 years with allergic rhinitis. Am J Rhinol Allergy. 2014;28(2):131-9.

47. Wei H, Zhang Y, Shi L, Zhang J, Xia Y, Zang J, et al. Higher dosage of HIFU treatment may lead to higher and longer efficacy for moderate to severe perennial allergic rhinitis. Int J Med Sci. 2013;10(13):1914-20.

48. Tatar EC, Surenoglu UA, Saylam G, Isik E, Ozdek A, Korkmaz H. Is there any correlation between the results of skin-prick test and the severity of symptoms in allergic rhinitis? Am J Rhinol Allergy. 2012;26(1):e37-9.

49. Bousquet PJ, Bousquet-Rouanet L, Co Minh HB, Urbinelli R, Allaert FA, Demoly P. ARIA (Allergic Rhinitis and Its Impact on Asthma) classification of allergic rhinitis severity in clinical practice in France. Int Arch Allergy Immunol. 2007:143(3):163-9.

50. Rouve S, Didier A, Demoly P, Jankowsky R, Klossek JM, Anessi-Maesano I. Numeric score and visual analog scale in assessing seasonal allergic rhinitis severity. Rhinology. 2010;48(3):285-91.

51. Baiardini I, Braido F, Brandi S, Tarantini F, Bonini S, Bousquet PJ, et al. The impact of GINA suggested drugs for the treatment of asthma on healthrelated quality of life: a GA(2)LEN review. Allergy. 2008;63(8):1015-30.

52. Yamamoto H, Yamada T, Sakashita M, Kubo S, Susuki D, Tokunaga T, et al. Efficacy of prophylactic treatment with montelukast and montelukast plus add-on loratadine for seasonal allergic rhinitis. Allergy Asthma Proc. 2012;33(2):e17-22.

53. Bousquet PJ, Bachert C, Canonica GW, Casale TB, Mullol J, Klossek JM, et al. Uncontrolled allergic rhinitis during treatment and its impact on quality of life: a cluster randomized trial. J Allergy Clin Immunol. 2010;126(3):666668.e1-5.

54. Demoly P, Bousquet PJ, Mesbah K, Bousquet J, Devillier P. Visual analogue scale in patients treated for allergic rhinitis: an observational prospective study in primary care: asthma and rhinitis. Clin Exp Allergy. 2013;43(8):881-8

55. Bousquet PJ, Combescure C, Klossek JM, Daures JP, Bousquet J. Change in visual analog scale score in a pragmatic randomized cluster trial of allergic rhinitis. J Allergy Clin Immunol. 2009;123(6):1349-54.

56. Vuurman EF, Vuurman LL, Lutgens I, Kremer B. Allergic rhinitis is a risk factor for traffic safety. Allergy. 2014;69(7):906-12.

57. Hellgren J, Cervin A, Nordling S, Bergman A, Cardell LO. Allergic rhinitis and the common cold-high cost to society. Allergy. 2010;65(6):776-83.

58. Zuberbier T, Lotvall J, Simoens S, Subramanian SV, Church MK. Economic burden of inadequate management of allergic diseases in the European Union: a GA(2) LEN review. Allergy. 2014;69(10):1275-9.

59. Lamb CE, Ratner PH, Johnson CE, Ambegaonkar AJ, Joshi AV, Day D, et al. Economic impact of workplace productivity losses due to allergic rhinitis compared with select medical conditions in the United States from an employer perspective. Curr Med Res Opin. 2006;22(6):1203-10.

60. Walker S, Khan-Wasti S, Fletcher M, Cullinan P, Harris J, Sheikh A. Seasonal allergic rhinitis is associated with a detrimental effect on examination performance in United Kingdom teenagers: case-control study. J Allergy Clin Immunol. 2007:120(2):381-7.

61. Nolte H, Nepper-Christensen S, Backer V. Unawareness and undertreatment of asthma and allergic rhinitis in a general population. Respir Med. 2006;100(2):354-62.

62. Bousquet J, Schunemann HJ, Hellings PW, Arnavielhe S, Bachert C, Bedbrook A, et al. MACVIA clinical decision algorithm in adolescents and adults with allergic rhinitis. J Allergy Clin Immunol. 2016;138(2):367-374. e2. doi:10.1016/j.jaci.2016.03.025.

63. Konig HH, Bernert S, Angermeyer MC, Matschinger H, Martinez M, Vilagut $\mathrm{G}$, et al. Comparison of population health status in six european countries: results of a representative survey using the EQ-5D questionnaire. Med Care. 2009:47(2):255-61.

64. Smith AF, Pitt AD, Rodruiguez AE, Alio JL, Marti N, Teus M, et al. The economic and quality of life impact of seasonal allergic conjunctivitis in a Spanish setting. Ophthalmic Epidemiol. 2005;12(4):233-42. 
65. Blanc PD, Trupin L, Eisner M, Earnest G, Katz PP, Israel L, et al. The work impact of asthma and rhinitis: findings from a population-based survey. J Clin Epidemiol. 2001;54(6):610-8.

66. Bousquet J, Bodez T, Gehano P, Klossek JM, Liard F, Neukirch F, et al. Implementation of guidelines for allergic rhinitis in specialist practices. A randomized pragmatic controlled trial. Int Arch Allergy Immunol. 2009;150(1):75-82.

67. Ohta K, Jean Bousquet P, Akiyama K, Adachi M, Ichinose M, Ebisawa M, et al. Visual analog scale as a predictor of GINA-defined asthma control. The SACRA study in Japan. J Asthma. 2013;50(5):514-21.

68. Hojo M, Ohta K, likura M, Mizutani T, Hirashima J, Sugiyama H. Clinical usefulness of a guideline-based screening tool for the diagnosis of allergic rhinitis in asthmatics: the Self Assessment of Allergic Rhinitis and Asthma questionnaire. Respirology. 2013;18(6):1016-21.

69. Sullivan PW, Smith KL, Ghushchyan VH, Globe DR, Lin SL, Globe G. Asthma in USA: its impact on health-related quality of life. J Asthma. 2013;50(8):891-9.

70. van der Leeuw S, van der Molen T, Dekhuijzen PN, Fonseca JA, van Gemert FA, Gerth van Wijk R, et al. The minimal clinically important difference of the control of allergic rhinitis and asthma test (CARAT): crosscultural validation and relation with pollen counts. NPJ Prim Care Respir Med. 2015;25:14107.

71. Ciprandi G, Schiavetti I, Sorbello V, Ricciardolo FL. Perception of asthma symptoms as assessed on the visual analog scale in subjects with asthma: a real-life study. Respir Care. 2016;61(1):23-9.

72. Belgrave DC, Buchan I, Bishop C, Lowe L, Simpson A, Custovic A. Trajectories of lung function during childhood. Am J Respir Crit Care Med. 2014;189(9):1101-9.

73. Bousquet J, Anto J, Sunyer J, Nieuwenhuijsen M, Vrijheid M, Keil T, et al. Pooling birth cohorts in allergy and asthma: European Union-funded initiatives - a MeDALL, CHICOS, ENRIECO, and GA(2)LEN joint paper. Int Arch Allergy Immunol. 2013;161(1):1-10.

74. Anto JM, Pinart M, Akdis M, Auffray C, Bachert C, Basagana X, et al. Understanding the complexity of IgE-related phenotypes from childhood to young adulthood: a Mechanisms of the Development of Allergy (MeDALL) seminar. J Allergy Clin Immunol. 2012;129(4):943-954.e4.

75. Bousquet J, Anto J, Auffray C, Akdis M, Cambon-Thomsen A, Keil T, et al. MeDALL (Mechanisms of the Development of ALLergy): an integrated approach from phenotypes to systems medicine. Allergy. 2011:66(5):596-604
76. Bousquet J, Anto JM, Akdis M, Auffray C, Keil T, Momas I, et al. Paving the way of systems biology and precision medicine in allergic diseases: the MeDALL success story. Allergy. 2016;71(11):1513-25. doi:10.1111/ all.12880.

77. Ballardini N, Bergstrom A, Wahlgren CF, van Hage M, Hallner E, Kull I, et al. IgE antibodies in relation to prevalence and multimorbidity of eczema, asthma, and rhinitis from birth to adolescence. Allergy. 2016;71(3):342-9.

78. Gabet S, Just J, Couderc R, Bousquet J, Seta N, Momas I. Early polysensitisation is associated to allergic multimorbidity in PARIS birth cohort infants. Pediatr Allergy Immunol. 2016;27(8):831-37. doi:10.1111/ pai.12622.

79. Burte E, Bousquet J, Varraso R, Gormand F, Just J, Matran R, et al. Characterization of rhinitis according to the asthma status in adults using an unsupervised approach in the EGEA study. PLOS ONE. 2015;10(8):e0136191.

80. Siroux V, Lupinek C, Resch Y, Curin M, Just J, Keil T, et al. Specific IgE and IgG measured by the MeDALL allergen-chip depend on allergen and route of exposure: the EGEA study. J Allergy Clin Immunol. 2016. doi:10.1016/j.jaci.2016.05.023.

81. Just J, Elegbede CF, Deschildre A, Bousquet J, Moneret-Vautrin DA, Crepet $A$, et al. Three peanut allergic/sensitized phenotypes with gender difference. Clin Exp Allergy. 2016:46(12):1596-1604. doi:10.1111/cea.12791.

82. Bresciani M, Paradis L, Des Roches A, Vernhet H, Vachier I, Godard $P$, et al. Rhinosinusitis in severe asthma. J Allergy Clin Immunol. 2001;107(1):73-80.

83. ten Brinke A, Grootendorst DC, Schmidt JT, De Bruine FT, van Buchem MA, Sterk PJ, et al. Chronic sinusitis in severe asthma is related to sputum eosinophilia. J Allergy Clin Immunol. 2002;109(4):621-6.

84. ten Brinke A, Sterk PJ, Masclee AA, Spinhoven P, Schmidt JT, Zwinderman $\mathrm{AH}$, et al. Risk factors of frequent exacerbations in difficult-to-treat asthma. Eur Respir J. 2005;26(5):812-8.

85. Wilson N, Bewick M, Dziworski W. Maintaining health despite chronic illness in the elderly: a multi-disciplinary study visit to the north of England region. Eur Geriatr Med. 2015;6(4):396-400

\section{Submit your next manuscript to BioMed Central and we will help you at every step:}

- We accept pre-submission inquiries

- Our selector tool helps you to find the most relevant journal

- We provide round the clock customer support

- Convenient online submission

- Thorough peer review

- Inclusion in PubMed and all major indexing services

- Maximum visibility for your research

Submit your manuscript at www.biomedcentral.com/submit
(OioMed Central 